\title{
Light regulation of metabolic pathways in fungi
}

\author{
Doris Tisch • Monika Schmoll
}

Received: 20 August 2009/Revised: 14 October 2009 / Accepted: 14 October 2009 / Published online: 14 November 2009

(C) The Author(s) 2009. This article is published with open access at Springerlink.com

\begin{abstract}
Light represents a major carrier of information in nature. The molecular machineries translating its electromagnetic energy (photons) into the chemical language of cells transmit vital signals for adjustment of virtually every living organism to its habitat. Fungi react to illumination in various ways, and we found that they initiate considerable adaptations in their metabolic pathways upon growth in light or after perception of a light pulse. Alterations in response to light have predominantly been observed in carotenoid metabolism, polysaccharide and carbohydrate metabolism, fatty acid metabolism, nucleotide and nucleoside metabolism, and in regulation of production of secondary metabolites. Transcription of genes is initiated within minutes, abundance and activity of metabolic enzymes are adjusted, and subsequently, levels of metabolites are altered to cope with the harmful effects of light or to prepare for reproduction, which is dependent on light in many cases. This review aims to give an overview on metabolic pathways impacted by light and to illustrate the physiological significance of light for fungi. We provide a basis for assessment whether a given metabolic pathway might be subject to regulation by light and how these properties can be exploited for improvement of biotechnological processes.
\end{abstract}

\footnotetext{
D. Tisch $•$ M. Schmoll $(\bowtie)$

Research Area Gene Technology and Applied Biochemistry, Institute of Chemical Engineering,

Vienna University of Technology,

Getreidemarkt 9/1665,

1060 Vienna, Austria

e-mail: monika.schmoll@tuwien.ac.at

D. Tisch

e-mail: doris.tisch@tuwien.ac.at
}

Keywords Light response - Metabolic pathways . Strain improvement $\cdot$ Biotechnological processes

\section{Introduction}

Light is a very important signal for every living cell, and since optimal adaptation to both the beneficial and harmful effects of light significantly enhances fitness of an organism, it can be considered crucial for successful competition and survival in nature. The ability to sense light is essential to recognize and anticipate conditions unfavorable for vegetative growth, such as loss of water and deprivation of nutrient on the soil surface. On the other hand, the same signal is needed for appropriate timing of production and dissemination of conidia, which happens on the surface, in light. Commonly observed effects of light on fungi range from induction or inhibition of sexual development and conidiation to circadian clock resetting and suppression of spore release (Corrochano 2007). However, also phenomena such as hyperpolarization of the cell membrane (Gresik et al. 1991; Potapova et al. 1984), alterations in intracellular levels of ATP and cyclic adenosine monophosphate (cAMP) as well as an increased rate of oxygen consumption and glycogen breakdown have been observed (Farkas et al. 1990).

In contrast to plants, fungi use light as a source of information but not as a source of energy. During decades of studies on fungi, at least 100 fungal species, representing all phyla, have been found to react to light (Marsh et al. 1959). They have perception mechanisms for blue, near UV, green, and red light (Herrera-Estrella and Horwitz 2007; Purschwitz et al. 2006). However, the influence of light on metabolic processes has not been investigated in that much detail in most cases, and therefore, the responses 
to light described in this review will predominantly refer to white light or daylight effects.

Although light-related signaling phenomena have mainly been studied in Neurospora crassa, influences on various metabolic processes and regulators have been elucidated in other fungi. Based on the genes involved in the light signaling cascade and their impact on metabolic output pathways in several fungi, hypothetical connections between these pathways and light signaling can be drawn, which may be worth exploring in the future. Yet, also direct metabolic responses to light have been discovered in fungi, in many cases already decades ago.

In the following, we will give an overview on the relevance of light for fungi as well as how fungi can perceive and transmit the light signal. We will then discuss processes directly influenced by light as well as such impacted by components of the light perception machinery and its downstream signaling cascade. Thereby, we intend to describe the network of factors targeted by light and subject to light response in fungi. Despite often similar output effects of illumination, differences in regulatory mechanisms of light response must be assumed between different fungal species. Nevertheless, the data summarized below indicate that the influence of light pulses on a certain metabolic pathway - both with respect to the enzymes constituting it and the signaling proteins and transcription factors regulating it - cannot be excluded without experimental prove. Although this network provided here will be a heterogeneous one, composed of pits and pieces of information from various fungi, it can help to comprehend how fungi adjust their metabolic pathways in order to survive and succeed in competition upon sunrise.

Conidiation as one suitable natural cause for precise timing with the aid of light

Nothing in biology makes sense unless it is in the light of reproduction (Dobzhansky 1973; Maheshwari 2007). In this respect, it could be speculated that every adaptation of metabolism to changing environmental cues is ultimately just meant to provide cellular energy needed for conidiation and/or sexual development in an appropriate amount at the ideal time and hence to ensure reproduction and survival of a species. Conidiation is the most obvious output regulated by the so-called circadian clock (which ensures ideal timing) and is initiated after dusk in Neurospora. Light pulses administered during subjective night perturb this timing and cause resetting of the clock and altered phases of conidiation (Devlin 2002; Brunner and Kaldi 2008). In many fungi, conidiation requires a light pulse to be initiated. The processes relevant for conidiation and its regulation are diverse. At several stages in the cascades leading to initiation of conidiation, mechanisms triggering the production of enzymes and chemicals the fungus applies for successful competition in nature are at work. In the physiological sense, the transition from vegetative growth (favored inside the substrate, i.e., in darkness) to the reproductive state (which mostly happens on the surface of the substrate - in light) can be anticipated to require drastic changes in metabolism. Still, considering the variations in favorable conditions for sexual or asexual development in different fungi, regulation of these changes may differ accordingly and caution is advisable when comparing or extrapolating data from one fungal species to another. Consequently, these often light-responsive adaptation mechanisms of a given organism can be used to gain a better understanding on biotechnological processes and to improve their efficiency.

The interrelationship between light and circadian rhythms

Circadian rhythms are apparently ubiquitous among eukaryotic organisms (Bünning 1973). Constant temperature and darkness are conditions imposed on the organism in the laboratory in order to facilitate and standardize experimental work. However, in nature, adaptation of an organism to changing temperature and light conditions is crucial for survival. Hence, a complex machinery for anticipation of dusk and dawn, adaptation to the harmful effects of light and desiccation during the day, and efficient timing of conidiation has evolved. The circadian rhythmsinternal timekeepers which generate a daily rhythmicityare present in light-sensitive organisms from cyanobacteria to humans. They have been studied in detail not only in $N$. crassa, which has been suggested as a model for understanding photoperiodism (Tan et al. 2004), but also in Aspergillus spp. and other organisms (Brunner and Kaldi 2008; Devlin 2002; Dunlap et al. 2007; Greene et al. 2003; Heintzen and Liu 2007). This circadian system is capable of sensing and interpreting changes in temperature and light conditions and has a major function in adaptation by adjusting its periodicity and phase (Heintzen and Liu 2007). Even light pulses in the range of minutes can reset this clock system. The photoperiod-comparable with the length of a day - can also have an influence on physiology of fungi, as was shown for example for infectivity of the insect pathogen Paecilomyces fumosoroseus (Avery et al. 2004). In Fusarium oxysporum, a role for the wc-1 homolog (a photoreceptor) in pathogenicity with mammals has been observed (Ruiz-Roldan et al. 2008). These findings are only special examples, which highlight the significance of reception of the light signal for fungi. The mechanisms dealing with response and adaptation to light on one hand and circadian rhythmicity on the other hand share several crucial regulatory components. Because of this interdependence of light response and circadian 
rhythmicity, both processes have to be considered if the effect of light on an organism-in particular under laboratory conditions - is to be assessed. The interrelationship between the clock and metabolic processes has been studied systematically in $N$. crassa (Correa et al. 2003) and genes with products involved in DNA metabolism, ribosome biogenesis in RNA metabolism, cell cycle, protein metabolism, carbon metabolism, nitrogen metabolism, and isoprenoid (including carotenoid) biosynthesis have been found to be under clock control (Dong et al. 2008). Thereby, the circadian clock does not only influence metabolism, which would make it just an output pathway, but metabolism is also involved in control of circadian oscillations (Roenneberg and Merrow 1999), thus constituting a complex and interdependent regulatory machinery. However, besides $N$. crassa and Aspergillus, detailed reports on circadian rhythms and their regulation are scarce, and in most fungi, the presence of circadian rhythmicity has not yet been shown. Nevertheless, it can be expected that every organism sensitive to light needs to deal with the changing environment during day and night. Hence, processes triggered by a circadian rhythm are likely to be subject to certain regulation by light pulses which would reset the clock.

How transmission of the light signal works

The perception and transmission of the light signal is organized by a complex regulatory network, which is interconnected with circadian rhythmicity by sharing crucial components (for reviews, see Brunner and Kaldi 2008; Dunlap and Loros 2004; Dunlap et al. 2007) in $N$. crassa. With respect to light response, the major regulatory proteins in this fungus are the PAS-domain containing photoreceptors WHITE COLLAR-1 (WC-1) and WHITE COLLAR-2 (WC-2) which act together as a transcription factor complex (white collar complex, WCC). All blue light responses in $N$. crassa described to date are mediated by the white collar complex. These photoreceptors are also key components of the circadian clock (Ballario et al. 1996; Crosthwaite et al. 1997; Linden and Macino 1997; Talora et al. 1999). Also, the WCC activates a number of clock-controlled genes, which serve as output of the clock mechanism.

Perception of the light signal is achieved by altered conformation and interaction: The LOV-type PAS domain of $\mathrm{WC}-1$ is responsible for the function of this protein as a photoreceptor and contains a signature motif for flavin binding, and between a conserved cysteine residue in the LOV domain and the flavin (FAD or FMN), a blue lightdependent adduct is formed (Crosson and Moffat 2002; Crosson et al. 2003). A photoinduced conformational change eventually leads to altered interaction properties with downstream signal transduction components and initiates transmission of the light signal (Crosson and Moffat 2002; Crosson et al. 2003; Harper et al. 2003).

Once perceived, the light signal causes entrainment of the clock, i.e., the light pulse is important for aligning the internal circadian clock to the real world. Studies on the $N$. crassa PAS/LOV domain protein VIVID (VVD) provided insight into the molecular pathways that are important for entrainment (Elvin et al. 2005; Heintzen et al. 2001). VVD represents a white collar-dependent blue light photoreceptor (Schwerdtfeger and Linden 2001, 2003), represses light responses, and is required for measuring changes in light intensities. It mutes WCC activity and regulates gating of the light response (Heintzen and Liu 2007; Heintzen et al. 2001; Fig. 1).

Photoreceptors homologous to the white collar proteins identified in $N$. crassa have been investigated also in Trichoderma atroviride (anamorph of Hypocrea atroviridis; Casas-Flores et al. 2006), Trichoderma reesei (anamorph of Hypocrea jecorina, Schmoll et al. 2005), Aspergillus nidulans (Purschwitz et al. 2008), and several other fungi (Idnurm and Heitman 2005; Idnurm et al. 2006). However, an ortholog of VVD has only been characterized in T. reesei (ENVOY, encoded by env1), and despite numerous corresponding data, complementation of a $v v d$-mutant strain failed to restore wild-type behavior in N. crassa. Hence, these proteins are no functional homologs (Schmoll et al. 2005).

Another important light regulatory protein identified in A. nidulans $(\mathrm{VeA})$ is encoded by velvet, which initially had

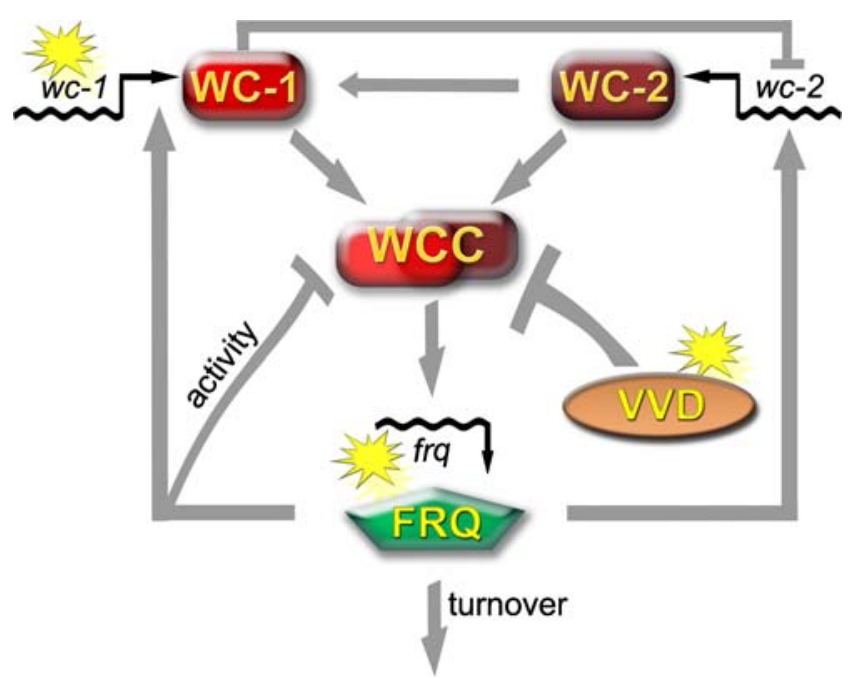

Fig. 1 Model for the function of the white collar complex (WCC) in N. crassa (adapted from Dunlap and Loros 2004). Light (yellow sun) influences the transcription of frequency $(f r q)$, vivid $(v v d)$, and white collar $1(w c-1)$. Through an as yet unknown posttranscriptional mechanism, FRQ promotes synthesis or accumulation of $\mathrm{WC}-1$ from existing $w c-1$ message. The components of the clock build a circadian feedback loop, in which WCC plays the central role. Arrows imply a positive regulation; lines ending with bars imply a negative one 
Fig. 2 Model for the function and localization of $\mathrm{VeA}$ (adapted from Bayram et al. 2008b). a In light, VeA is predominantly localized in the cytoplasm and VelB supports asexual sporulation. LaeA shows low activity. b In darkness, an increased amount of $\mathrm{VeA}$ is imported into the nucleus by KapA

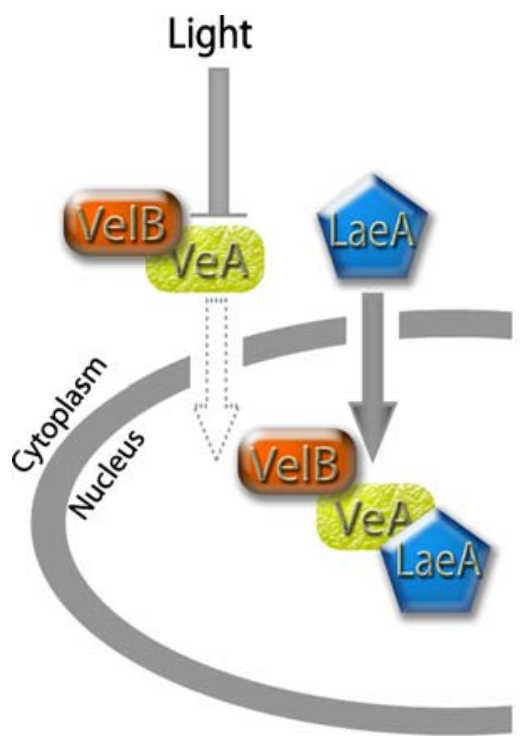

Dark

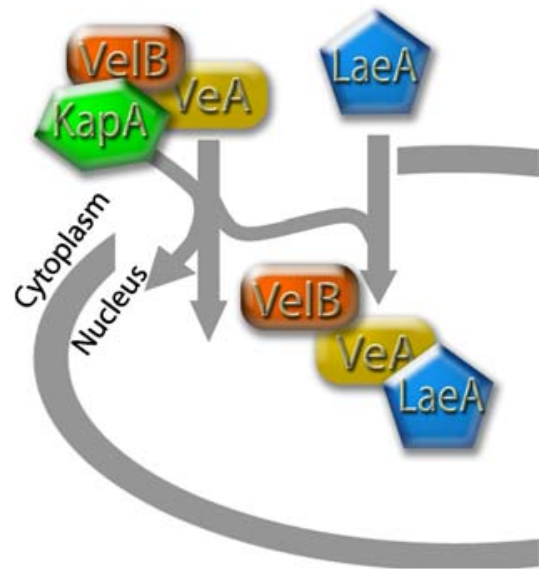

been implicated regulation of conidiation (Mooney and Yager 1990). VeA is involved in activation of sexual development and inhibition of asexual development and additionally functions as a key global metabolic regulator in the biosynthesis of many secondary metabolites (for a review, see Calvo 2008). Identified already in 1965 (Kafer 1965), the mechanism of its involvement in light response has only recently become subject to detailed studies. A connection between fruiting body formation, secondary metabolism, and light has been shown (Busch et al. 2003; Kato et al. 2003; Kim et al. 2002), and velvet, which is primarily expressed in the dark (Bayram et al. 2008b), may be one factor on the crossroads of the underlying pathways (Dreyer et al. 2007; Krappmann et al. 2005; Li et al. 2006). Transport of VeA into the nucleus is inhibited by light (Fig. 2), and it acts as a negative regulator of asexual development (Mooney and Yager 1990) and antibiotic production (Sprote and Brakhage 2007). A complex consisting of VeA, the velvet-like protein VelB, and LaeA, a master regulator of secondary metabolism in Aspergilli, connects light-responding developmental regulation and control of secondary metabolism (Bayram et al. 2008b). On the other hand, the bridge to light response is constituted by an interaction of VeA with the phytochrome-like red light receptor FphA, thus forming a complex which also comprises LreA and LreB (Fig. 3), the A. nidulans orthologs of the $N$. crassa photoreceptors WC-1 and WC-2 (Purschwitz et al. 2008, 2009).

Blue light is also perceived by cryptochromes, which are believed to have evolved from the photolyase protein family. These photoreceptors regulate entrainment by light of the circadian clock in animals and plants (Lin and Todo 2005). In fungi, cryptochrome/photolyase-like proteins have been described from T. atroviride (PHR1; BerrocalTito et al. 2007), A. nidulans (CryA; Bayram et al. 2008a),

Cercospora zeae-maydis (PHL1; Bluhm and Dunkle 2008), and the CRY-DASH-type photolyase/cryptochrome from Sclerotinia sclerotiorum (Veluchamy and Rollins 2008). The output effects of these photoreceptors include regulation of the veA gene, UV protection, and functions in development.

Besides the rather direct transmitters of the signal, the regulatory mechanism further includes light-dependent gene regulation by protein kinase $\mathrm{C}$ (PKC) in $N$. crassa (Arpaia et al. 1999). Upon activation of this kinase, it interacts with WC-1 in a light-dependent manner, phosphorylates it, and leads to decreased WC-1 protein levels (Franchi et al. 2005; Loros 2005). Processes regulated by PKC consequently are likely to be also influenced by light because once activated, PKC not only acts on the respective process but apparently also interferes with light response. This finding suggests that the signal transmitted via PKC has a light-dependent relevance. In this respect, it is interesting that inositol metabolites play an indirect role in the light input pathway in $N$. crassa. In this fungus, inositol depletion increases light sensitivity by several orders of magnitude. This effect is suggested to be caused by a lack

Fig. 3 Model for the VeA protein complex (adapted from Calvo 2008). VeA interacts with the phytochrome-like red light sensor FphA, where the chromophore-binding region in this protein is essential for maintenance of this interaction. FphA in turn interacts with the photoreceptor homolog LreB and hence connects VeA to the $A$. nidulans equivalent of the N. crassa WCC

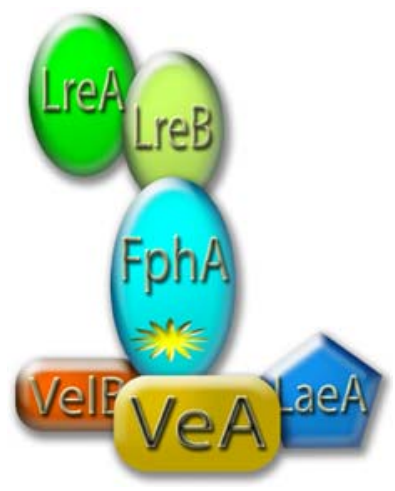


of inositol leading to increased levels of diacylglycerol and to consequently enhanced protein kinase $\mathrm{C}$ activity (LakinThomas 1992).

Also, another kinase is essential for clock function in $N$. crassa: cAMP-dependent protein kinase A (PKA), the function of which has been well studied with several metabolic processes. This kinase inhibits WC activity by serving as a priming kinase for the subsequently acting casein kinases (Huang et al. 2007). For both kinases, a function in conidiation has been shown (Banno et al. 2005; Herrmann et al. 2006), which might be the physiological reason for their function in light response and regulation of metabolic processes. Additionally, also regulatory cycles involving the clock component FREQUENCY (FRQ), which activates or deactivates the WCC (Fig. 1), are controlled by phosphorylation events (Heintzen and Liu 2007), hence emphasizing that phosphorylation is a crucial event in triggering circadian timing and light response.

What would happen if we let the sun rise?

An early study on blue light-induced genes in 1989 (Sommer et al. 1989) started the endeavor to answer the question: How many genes are regulated by blue light, in what way, and how do they influence the organism? This analysis revealed that as early as $2 \mathrm{~min}$ after the blue light signal, transcripts are detectable and the authors estimated that within $30 \mathrm{~min}, 60-80$ genes are regulated in $N$. crassa. It can, however, be assumed that initiation of transcription after illumination already starts much earlier, since for example, only $2 \mathrm{~s}$ of light is sufficient to induce sporulation in Trichoderma viride (Betina and Zajacova 1978). Thus, transcription of genes involved in this process must have been triggered by this $2 \mathrm{~s}$ of light. Later on, a similar study dealing with light regulation of expression of the toxin cercosporin by Cercospora kikuchii led to the identification of six light-enhanced cDNA clones, transcript accumulation of which paralleled cercosporin production (Ehrenshaft and Upchurch 1991). Also, the role of the photoreceptor WC-1 in light response was investigated on a broad scale in $N$. crassa by microarray analysis (Lewis et al. 2002) and functions of homologs of WC-1, WC-2, and VVD were elucidated on a genome-wide scale in Trichoderma spp.: T. atroviride was shown to regulate gene expression not only in response to blue light but also to red light and that the respective signaling pathways are interconnected. Moreover, this fungus exhibits blue light regulator (BLR; orthologs to the white collar proteins)-independent photoresponses (Rosales-Saavedra et al. 2006). For T. reesei, different growth patterns in light and darkness have been detected on various carbon sources, and these patterns were altered in a strain lacking the light regulatory protein ENVOY (Schmoll et al. 2005; Schuster et al. 2007). In agreement with this report, crosstalk between carbon metabolism, blue light receptors, and reaction to oxidative stress was shown by investigation of growth of $T$. atroviride on 96 carbon sources (Friedl et al. 2008a). On a similarly broad scale, it was shown that conidiation is primarily carbon source dependent and illumination plays a catalytic role in T. atroviride. Also, the study revealed cross talk of the photoreceptors BLR-1 and BLR-2 (homologs of $N$. crassa WC-1 and WC-2) with regulation of cyclic AMP levels (Friedl et al. 2008b).

Recent comprehensive genome-wide approaches provide a broad picture on the transcriptional response to light. In $N$. crassa, more than $5 \%$ of the total detectable transcripts are responsive to light. Also, a differentiation between early light-responsive genes (ELRGs), which peak between 15 and $45 \mathrm{~min}$ after onset of light, and late light-responsive genes (LLRGs), which peak later until $90 \mathrm{~min}$ after lights on, is possible (Chen et al. 2009). While ELRGs essentially represent the attempt to rapidly adapt to the harmful effects of light, such as genes involved in synthesis of photoprotective pigments, secondary metabolism, and signaling, LLRGs rather reflect adjustment of metabolic functions to daylight condition, as they comprise genes involved in carbohydrate metabolism, oxidation of fatty acids, and detoxification. In summary, this study revealed a tightly scheduled sequence of cellular events in response to the daily light stimulus in N. crassa (Chen et al. 2009).

Aiming to provide insights into the systems biology of the clock in Neurospora, a recent study revealed that ribosomal RNA processing and assembly rather than transcription seems to be under clock control, suggesting an unexpected mechanism of posttranscriptional regulation of clock-controlled genes (Dong et al. 2008). In support of this finding, light-dependent splicing of the $T$. viride hydrophobin gene tvsrhl was reported (Vargovic et al. 2006). In F. oxysporum, also differential splicing of a hydrophobin was observed. In this case, this phenomenon was dependent on the presence of the WC-1 homolog (Ruiz-Roldan et al. 2008). Consequently, a role of this photoreceptor in light-dependent differential splicing-not only of hydrophobin genes - could explain discrepancies between transcript abundance and protein accumulation or functionality in light.

\section{Metabolic pathways as output pathways of light signaling}

Literature shows that the fundamental adaptations fungi apply to survive and succeed in the daily changes brought about by the rotation of earth are largely underestimated. While numerous studies deal with light regulation of carotenoid metabolism, the implications of early studies 
suggesting an influence of light on other metabolic processes (for example, Hill 1976; Nambudiri et al. 1973; Ram et al. 1984) were often not considered with later studies on transcription and expression of metabolic genes. At the same time, an increasing number of reports show that a significant portion of the transcribed genes of an organisms responds to light (Chen et al. 2009; Sommer et al. 1989), often within minutes. Additionally, it can be assumed that this response is influenced by the carbon source the fungus grows on (Friedl et al. 2008a, b; Schuster et al. 2007). Quite early on it was recognized that the nature of the medium on which the fungus is cultivated can determine whether light stimulates or decreases the growth rate in many fungi (Carlile 1965). This phenomenon becomes very clear in recent studies investigating growth and conidiation on 96 carbon sources in wild-type and mutant strains of T. atroviride (Friedl et al. 2008a, b). Substantial metabolic differences have been detected between cultures growing in light and darkness. Light seems to have a different effect in dependence on whether the nutritional conditions are optimal or not. Hence, under optimal conditions, light and dark metabolism should be approximately equally effective in supporting growth, but alterations in conditions would affect the processes differently (Carlile 1965).

In the following, we will summarize both quite early and very recent studies dealing with light-responsive regulation of transcription of genes involved in metabolic pathways, activation of enzymes, alterations of nutrient uptake, and production of metabolites. The genes and enzymes described were assigned to a chapter according to the classification of the MIPS Functional Catalogue (FunCatDB; Ruepp et al. 2004). Nevertheless, in some cases, overlaps were unavoidable in order to maintain clarity.

\section{Carotenoid metabolism}

Carotenoids are soluble pigments produced in bacteria, fungi, and plants (Britton et al. 1998). They belong to the group of terpenoids and comprise over 600 organic pigments, split into two classes: xanthophylls (which contain oxygen) and carotenes (contain no oxygen). These pigments can act as antioxidants and generally absorb blue light, which is crucial for their function in numerous organisms from bacteria to plants. Besides their natural, mainly protective function in the organisms producing carotenoids, these molecules also have beneficial effects on animals and humans (Stahl and Sies 2005), who are not able to produce carotenoids. This is also the main reason why they are produced on a large scale both chemically as well as biotechnologically (Avalos and Cerda-Olmedo 2004). Investigations of carotenoid production in fungi (Fig. 4) have already been done more than 100 years ago

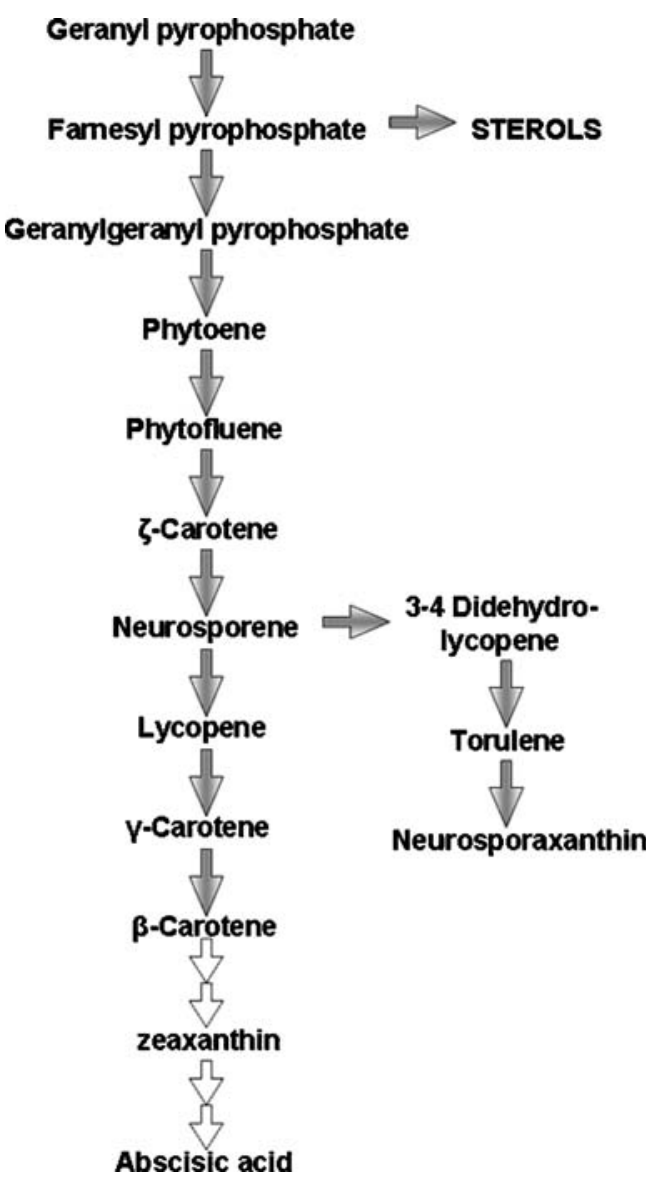

Fig. 4 Biosynthetic pathway for $\beta$-carotene in the Mucorales and neurosporaxanthin in Neurospora. Conversion of $\beta$-carotene to abscisic acid (empty arrows) has only been shown in Cercospora rosicola, but in no other fungus (Assante et al. 1977)

(Kohl 1902) and elaborate studies with Phycomyces blakesleeanus followed in the 1950s (Bergman et al. 1969; Garton et al. 1951; Meissner and Delbruck 1968). Among the many fungi-producing carotenoids, the zygomycete Blakeslea trispora and the Mucorales P. blakesleeanus and Mucor circinelloides are of industrial interest, but several other fungi also deserve closer evaluation with respect to their carotenoid production. While the respective biosynthetic pathways are quite conserved, regulation of carotenoid production (Almeida and Cerda-Olmedo 2008; Cerda-Olmedo 2001) is more variable among species. Nevertheless, blue light is a common signal triggering upregulation of the pathway (Avalos et al. 1993; Avalos and Cerda-Olmedo 2004; Carlile 1965; Jayaram et al. 1979). P. blakesleeanus is well studied with respect to its response to light and its production of carotenoids. Besides sexual stimulation, also light has an enhancing effect on carotenoid production in this fungus (Cerda-Olmedo 2001). Blue light causes enhanced accumulation of $\operatorname{carR} A$ and $\operatorname{car} B$ transcripts (Blasco et al. 2001; Rodriguez-Romero and Corrochano 2004; Ruiz-Hidalgo et al. 1997), encoding 
enzymes of the carotenoid biosynthetic pathway, which are crucial for light response and carotenogenesis in P. blakesleeanus (Bejarano et al. 1991). A similar effect has been observed for the homologs of these genes in M. circinelloides (Velayos et al. 2000a, b), B. trispora (Quiles-Rosillo et al. 2005), and N. crassa (Nelson et al. 1989; Schmidhauser et al. 1990, 1994). The so-called mad mutants of Phycomyces (denominated after Nobel laurate Max Delbrück), which are defective in phototropism, show a corresponding effect: Deletion of $\operatorname{mad} A$ and $\operatorname{mad} B$ leads to defective photocarotenogenesis (Cerda-Olmedo 2001; Idnurm et al. 2006). While both brief light pulses as well as prolonged illumination increase carotene accumulation in Phycomyces (Bejarano et al. 1991), continuous illumination results in even decreased carotene production in Blakeslea (Sutter 1970). Yet it shows clear enhancement after illumination of dark-grown mycelia in this fungus (QuilesRosillo et al. 2005). With respect to regulation, it is interesting that in Phycomyces, a heterotrimeric G-protein apparently plays a role photocarotenogenesis (Tsolakis et al. 2004).

Besides these industrially important fungi, also Gibberella fujikuroi (Fusarium moniliforme) produces considerable amounts of carotenoids (predominantly neurosporaxanthin and minor amounts of intermediate carotenes), and hence, when grown in light, mycelia of this fungus are orange (Avalos and Schrott 1990). In darkness, mycelia are white and have a low carotenoid content, albeit several mutants, called pale-orange, contain an increased amount of carotenoids even in darkness (Avalos and Cerdà-Olmedo 1987). In contrast to Neurospora, which already responds to a few seconds of illumination with carotenoid production (Schrott 1980), G. fujikuroi needs at least $8 \mathrm{~min}$ of light for a detectable response (Avalos and Schrott 1990). Moreover, G. fujikuroi still considerably responds to illumination by carotenoid production upon deletion of the photoreceptor homolog $w c-1$, albeit to a lesser extent than the wild type (Estrada and Avalos 2008; Ruiz-Roldan et al. 2008). Studies on the interrelationship of the positive effect of nitrogen starvation on carotenogenesis and the effect of light revealed that these effects are additive (Rodriguez-Ortiz et al. 2009).

In $N$. crassa, carotenoid metabolism and its regulation by light and the circadian clock has been studied extensively predominantly because it is a convenient output pathway of these regulatory circuits. Also in this fungus, carotenoid biosynthesis is being studied already for decades (Harding et al. 1969), and carotenoids have been implicated in protection of respiratory systems in this fungus (RamadanTalib and Prebble 1978). As might be expected from the importance of the light signal for carotenogenesis, the photoreceptors WC-1 and WC-2 both are important regulators of this process, and mutants in the respective genes are significantly impaired in its regulation (Nelson et al. 1989;
Perkins et al. 1982). On the other hand, the photoreceptor protein VVD has a negative effect on carotenogenesis, and $v v d$ mutants show a vivid orange color when grown in light, reflecting overproduction of carotenoids, which also gave this gene its name (Heintzen et al. 2001; Shrode et al. 2001). Biosynthetic enzymes of the carotenoid pathway such as AL-1 (Schmidhauser et al. 1990), the phytoene synthase AL-2 (Schmidhauser et al. 1994), the prenyl transferase AL-3 (Sandmann et al. 1993), and CAO-2 are regulated by light in a WC-1 and WC-2 dependent manner (Saelices et al. 2007). Exposure of mycelia to open air is crucial for photocarotenogenesis, and reactive oxygen species (ROS) play a major role in this process (Iigusa et al. 2005). Also, a function of the putative green light opsin photoreceptor NOP-1 in carotenogenesis has been suggested (Bieszke et al. 2007).

The clear light regulation of carotene biosynthesis in fungi suggested a similar effect in regulation of a closely related compound, ubiquinone, which shares the majority of biosynthetic reactions with carotene. It has been shown that carotenoid protects ubiquinone from photodestruction in mitochondria (Ramadan-Talib and Prebble 1978). Ubiquinone is an essential cellular component, which is used as an ingredient in cosmetics and for medical applications (Kuzina and Cerda-Olmedo 2007 and references therein). A comparable regulation of its production to carotenoid biosynthesis would greatly facilitate strain improvement. Interestingly, studies with B. trispora and $P$. blakesleeanus revealed that light indeed had a positive effect on the former (albeit a moderate one), but no effect on the latter (Kuzina and Cerda-Olmedo 2007). Hence, carotenoid and ubiquinone biosynthesis are not coregulated, and also, their regulation is not conserved between species.

Another compound derived from carotenoids (ABA) is abscisic acid, an important plant hormone (Gubler et al. 2005). This secondary metabolite is produced not only in plants but also in the fungus Cercospora rosicola, and as would be expected for a carotenoid derivative, it is also significantly regulated by light (Norman et al. 1981).

\section{Polysaccharide/carbohydrate metabolism}

The finding that deviation from optimal conditions causes different effects of light and darkness on growth of fungi (Carlile 1965) as do different carbon sources (Friedl et al. 2008a, b) indicates that carbon source availability and quality are closely interlinked with light response. It seems that not only utilization but also uptake of nutrients is subject to regulation by light (Hill 1976), which in turn impacts metabolism due to the lack of the respective compound in the cell. Inhibition of growth could thereby be caused by limited uptake of an essential nutrient. In Aspergillus ornatus, glucose uptake (but not lysine uptake) is significantly decreased upon cultivation in light. This 
could be interpreted in a way that the rate of glucose uptake is decreased prior to production of conidia. It has been suggested that this effect is due to biosynthesis of a dialyzable inhibitor of glucose uptake in light (Hill 1976), which is supported by data on Neurospora: In this fungus, it was shown that altered banding in a mutant strain is due to glucose transport deficiency (Halaban 1975). The interrelationship of this effect to conidiation is further emphasized by the finding that high glucose concentrations inhibit conidiation in T. viride, although they have no influence on growth (Betina and Zajacova 1978). Consequently, the limitation of glucose uptake in light may serve as a precondition for induction of conidiation. In support of these data, a study aimed at identification of early lightregulated genes in $T$. reesei revealed two putative transporters to be regulated by light and by the light regulatory protein ENVOY (Schuster et al. 2007).

Light also controls several metabolic processes of Aspergillus giganteus. In this fungus, occurrence of certain polysaccharides (Fiema 1983; Fiema and Golbiewska 1981) as well as the amount of glucans (Fiema et al. 1991) or glycogen content (Zurzycka 1991) depends on light intensity and at least in part on glucose concentration in the nutrient medium. Accordingly, a decrease in endogenous reserves, as reflected by a lower glycogen content upon cultivation in light, has also been observed in T. reesei (Farkas et al. 1990).

However, not only uptake but also intracellular synthesis and/or degradation of carbohydrates is altered in response to illumination, as are certain steps of glycolysis, the pentose phosphate pathway, or the citric acid cycle. The effects of light on intermediates of glycolysis reported from several different fungi as outlined in the following are summarized in Fig. 5.

In Penicillium isariiforme, polysaccharide synthesis is stimulated by light (Graafmans 1976). Blue light also causes increased excretion of citric acid in this fungus because of the lower supply of pyruvate in light, which is carboxylated to form citric acid via oxaloacetate. In light, higher levels of intermediates such as glucose-6-phosphate, glucose-1-phosphate, and fructose-6-phosphate were observed (Graafmans 1977). In this fungus, light stimulates the pentose phosphate pathway and blocks the supply of pyruvate for citric acid synthesis via the Embden-MeyerhofParnas (EMP) pathway. Since uptake of sucrose is not altered in light in P. isariiforme (Graafmans 1974), this indicates that less endogenous substrate is channeled via the glycolytic EMP pathway upon growth in light (Graafmans 1977).

Influences of light on carbohydrate metabolism are also present in P. blakesleeanus (Rua et al. 1987). The metabolites fructose 6-phosphate, glyceraldehyde 3phosphate, dihydroxyacetone phosphate, and lactate were present in higher concentrations in light, whereas glucose 6-

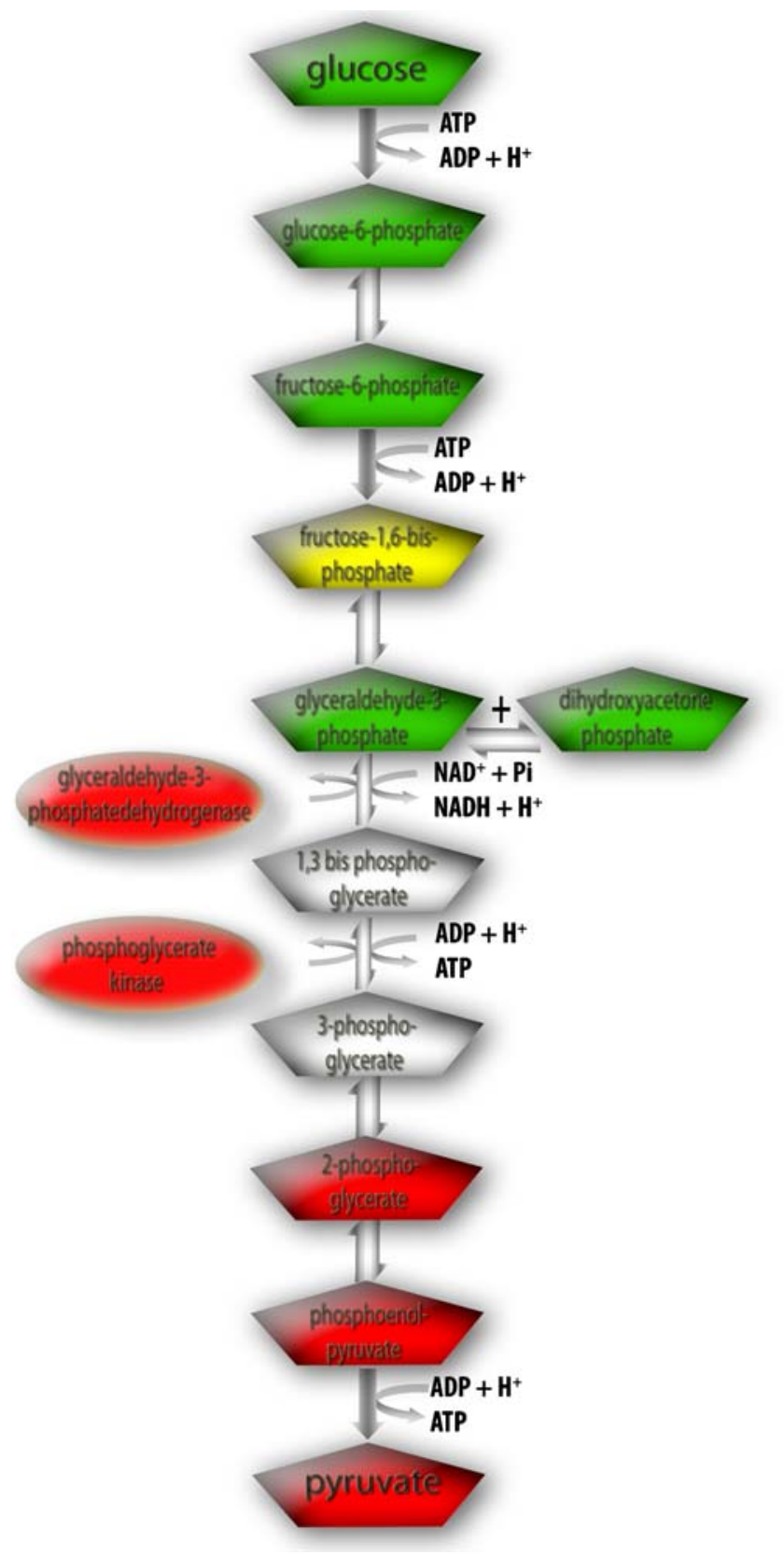

Fig. 5 Schematic representation of the influence of light on glycolysis. Green diamonds indicate increased levels of the respective metabolite upon cultivation in light, and red diamonds reflect lower levels. For fructose-1,6-bisphosphate (yellow diamond), no alteration was found, and in case of white diamonds, no data on the levels of these metabolites in light were available. Red balloons indicate lower enzymatic activities of the respective enzyme

phosphate, 2-phosphoglycerate, phosphoenolpyruvate, and pyruvate accumulated in cultures grown in darkness. The concentration of fructose 1,6-bisphosphate appeared to be light independent. With respect to pyruvate metabolism, levels of acetyl coenzyme A and citrate were higher in light, and L-alanine and L-malate were higher in darkness (Rua et al. 1987). 
While the molecular mechanisms underlying regulation of glucose uptake have not fully been elucidated on a molecular level so far, light-dependent differences in regulation of biosynthesis and activity of enzymes (which could explain the different levels of metabolic intermediates) provide a first look behind the scenes: The enzymes responsible for biosynthesis of the metabolites modulated by light in $P$. blakesleeanus are apparently partially regulated by light, but not all of them are dependent on the mad gene products or carotene biosynthesis. Glyceraldehyde 3-phosphate dehydrogenase and glucose-6-phosphate dehydrogenase are photoregulated and independent of both mad-gene products as well as carotene biosynthesis, while photoregulation of malate dehydrogenase appeared to be indeed dependent on the mad and carS genes. On the other hand, pyruvate kinase and lactate dehydrogenase are light independent as is the action of ATP and fructose 1,6-bisphosphate on the enzymes studied (Rodriguez-Aparicio et al. 1987). Glyceraldehyde-3phosphate dehydrogenase has moreover been identified as a clock-controlled gene ( $\mathrm{ccg}-7)$, but is not developmentally regulated in $N$. crassa. Both mRNA and activity of this enzyme show rhythmic regulation (Shinohara et al. 1998).

An early attempt to reveal influences of light on primary metabolism in fungi already showed changes in activities of several enzymes of carbohydrate metabolism (Ram et al. 1984): Activities of mitochondrial isocitrate dehydrogenase and malate dehydrogenase decreased, and cytosolic malate dehydrogenase of $N$. crassa increased upon cultivation in light. Glucose-6P-dehydrogenase, cytosolic isocitrate dehydrogenase, and isocitrate lyase also showed decreased activity upon illumination. The output of these light effects is also likely to be at least in part responsible for enhanced carotenoid (likely due to higher levels of acetyl-CoA) and lipid biosynthesis (see below). The increased protease activity that has been detected could also contribute to turnover rates of numerous enzymes (Ram et al. 1984), and protein secretion of several proteins has been reported to be altered upon cultivation in light in N. crassa (Kallies et al. 1992). Interestingly, this effect has not been observed with the largely "blind" $w c-1$ (photoreceptor) mutant strain. Accordingly, upregulation of genes involved in protein turnover was also observed upon illumination of mycelia of T. reesei (Schuster et al. 2007), and protein content in lightgrown cells of Blastocladiella emersonii was found to be increased by more than 30\% (Goldstein and Cantino 1962).

Also in $B$. emersonii, light stimulates polysaccharide synthesis and reduces glucose-6-phosphate dehydrogenase activity (Goldstein and Cantino 1962). The polysaccharide content of mycelia reached a twofold higher final concentration in light-grown cells than in those grown in the dark. Hence, these events may be related, and the increased polysaccharide content may be due to the diminished glucose oxidation caused by lower activity of the enzyme (Carlile 1965).

Even presumable housekeeping genes-which were considered constitutive and therefore not regulated by environmental cues such as phosphoglycerate kinase $(p g k)$ and glyceraldehyde-3-phosphate dehydrogenase $(g p d)$-are reported to be downregulated during conidiation after a light pulse in Trichoderma (Goldman et al. 1992; Puyesky et al. 1997). These findings are particularly important for analysis of gene transcription, since $g p d$ is frequently used as a reference gene. However, because of the unavoidable light pulses introduced during manipulation and harvesting of mycelia, regulation of gpd could jeopardize reliability of data, and its use should be reconsidered.

Taken together, the data on intermediary metabolites of glycolysis - combined from reports on different fungireveal a very interesting picture (Fig. 5): Conversion of glucose via several steps to glyceraldehyde-3-phosphate seems to be enhanced, while further downstream in the cascade glyceraldehyde-3-phosphate dehydrogenase and phosphoglycerate kinase, the activity of which is decreased in light, apparently inhibit the metabolic flux to a certain extent resulting in lower levels of the respective downstream metabolites. Intriguingly, the part of the cascade which is promoted in light consumes ATP, whereas the seemingly decreased pathway would produce ATP. Essentially, this would result in a decreased ATP output from glycolysis. However, a hypothesis of generally decreased ATP production in light is not supported by data on concentration ATP and ADP upon illumination in T. viride. Here, a transient increase in ATP levels and, to a lesser extent, in ADP levels shortly after illumination was observed. Moreover, this effect was additionally dependent on the light intensity (Farkas et al. 1985; Tamova et al. 1995). Still, it has to be kept in mind that these data only reflect the short period of about 15 min after illumination, in contrast to the cultivation in constant light used in most experiments described above.

Another interpretation for this phenomenon could be that the equilibrium between glyceraldehyde-3-phosphate and dihydroxyacetone phosphate is shifted toward the latter one, which after conversion into glycerol-3-phosphate could subsequently contribute to biosynthesis of the enhanced levels of fatty acids as detected in N. crassa in light (Ram et al. 1984). The enhanced supply of glucose and glucose-1phosphate (which is converted to glucose-6-phosphate) might also be due to stimulated degradation of glycogen (Farkas et al. 1990), which would be in agreement with the model. Nevertheless, these interpretations are highly speculative at the current stage of knowledge and should only be considered a starting point for further investigations.

As can be expected from the data outlined above, light also influences regulation of hydrolytic enzymes needed for 
degradation of extracellular substrates. It is difficult to determine at which physiological process the light signal interferes: Diminished uptake of substrate in response to light could necessitate slower or altered metabolism. On the other hand, if intracellular processes involved in utilization of the substrate would be working at different levels in light, also uptake of a carbon source could be adjusted accordingly. Together, regulation of these processes in turn could lead to adjustment of expression of extracellular enzymes in light-which would in turn influence the abundance of their degradation products to be taken up by the fungal cell. In this respect, the latter part of the circuit only applies if the organism is forced to degrade an extracellular, insoluble compound such as the natural substrates cellulose or lignin. However, also this extracellular section of the circuit has been shown to be responsive to light in that enzymes directly responsible for degradation of nutrients outside the fungal cell along with some intracellular degradative enzymes show light-dependent variation in activity or abundance:

Glucoamylase activity of blue light-exposed mycelia of Aspergillus niger is increased more than 2.5-fold as compared to mycelia grown in darkness (Zhu and Wang 2005), and light-grown cultures of $P$. blakesleeanus exhibit lower specific activities for alcohol dehydrogenase than dark-grown cultures. Since this effect has also been observed in mutants with altered phototropism, this adaptation is not mediated by the mad photosystem (Garce's and Medina 1985). Recent studies dealt with the regulatory mechanisms involved in light-responsive processes in carbohydrate metabolism. In A. nidulans, a role for VeA (besides its well-studied function in secondary metabolism as discussed below) in regulation of a fructosyl amino acid oxidase (Jeong et al. 2002) and a mannoprotein (Jeong et al. 2003) has been detected.

A screening for genes involved in cellulase signaling in the cellulolytic fungus $T$. reesei led to the identification of an ortholog of the N. crassa photoreceptor VIVID (Schmoll et al. 2004). In the following, cellulase gene expression was shown to be modulated by light. The identified protein, ENVOY (Schmoll et al. 2005), was not only shown to strongly respond to light but also to significantly influence cellulase gene expression in $T$. reesei. Subsequently, further parts of the signaling cascade were shown to have a lightdependent effect on cellulase gene expression. The G-alpha subunit GNA3 positively regulates this process only in light (Schmoll et al. 2009), while deletion of another G-alpha subunit, GNA1 (Seibel et al. 2009), leads to abolished cellulase transcription in light and strongly increased transcript levels in darkness. In both cases, constitutive activation of the G-alpha subunit did not lead to inducer independent cellulase expression. Hence, it can be concluded that these two G-alpha subunits transmit signals important for adjustment of cellulase gene expression to environmental conditions, the relevance of which depends on whether the fungus is growing in light or darkness. These signals are obviously not related to the presence of cellulose, and consequently, other so far undetermined environmental cues are highly relevant for regulation of cellulase expression and possibly other extracellular enzymes.

\section{Chitin and other cell wall components}

Upon illumination of fungal mycelia, the cell wall is the first site of impact of photons. Given the harmful effects of light, it is not surprising that several studies revealed an altered composition of the cell wall in response to light. Transient alterations in cell wall structure were observed in $P$. blakesleeanus (Herrera-Estrella and Ruiz-Herrera 1983), and the content of chitin in the cell wall of A. giganteus is doubled if the mycelium is cultivated in light as compared to darkness (Fiema 1983). In this fungus, the levels of S- and R-glucans in the mycelium show alterations in light. The Sglucan proportion is directly proportional to light intensity upon growth in high glucose concentrations. Also the relation between S- and R-glucans is altered. Therefore, both quality and quantity of glucans in the mycelium of A. giganteus are controlled by light and glucose concentration (Fiema 1993). In agreement with these findings, also illumination of Trichoderma harzianum affects enzymes involved in biosynthesis of cell wall components: Already after $10 \mathrm{~min}$ of illumination, specific activity of beta-1,3glucan synthase increases by about $130 \%$, and specific activity of chitin synthase decreases by $50 \%$ compared to dark controls. Correspondingly, while the chitin content remains essentially constant, the beta-1,3-glucan content in illuminated mycelia is elevated by up to $50 \%$ (Nemčovič and Farkaš 2001).

In P. blakesleeanus, studies on the fascinating phenomena of phototropism, gravitropism, and avoidance led to the identification of ten genes involved in these processes, the so-called mad genes. All of them show an altered response to light. The corresponding gene products have been suggested to be involved in regulation of growth of the cell wall in the growing zone, which may be due to lightregulated interplay of chitinases and new chitin synthesis (Cerda-Olmedo 2001). In this process, chitin synthase activity is increased by illumination and two lightsensitive calcium and calcium/calmodulin systems contribute to this activation (Herrera-Estrella and Ruiz-Herrera 1983; Ruiz-Herrera et al. 1990).

Fatty acid metabolism

Considering the global picture of gene regulation provided by the detailed microarray analysis of Chen and coworkers, 
which revealed upregulation of genes assigned to lipid metabolism and fatty acid oxidation (Chen et al. 2009), earlier studies on this topic now get additional support. It has been suggested that 18:2 polyunsaturated fatty acids (i.e., linoleic acid) have a role in fungal development, particularly in sporulation (Roeder et al. 1982). In Neurospora, oleic acid is the predominant fatty acid in developing asci and ascospores, while linoleic acid is the major fatty acid in asexual mycelia in this fungus (GoodrichTanrikulu et al. 1998). The concentration of lipids in $N$. crassa was found to be higher in mycelia grown in light as compared to cultivation in darkness (Ram et al. 1984). Similar results were obtained for Alternaria alternata (Haggblom and Unestam 1979). Provision of reducing power (which could be met by glucose-6P-dehydrogenase) and availability of acetyl CoA (which can be provided by cleavage of excess citrate in the cytosol) both can increase lipid as well as carotenoid levels. If light influences these preconditions, the respective regulation would explain how the influence of light is mediated. However, glucose-6Pdehydrogenase activity is not increased in Neurospora, on the contrary, but cytosolic malate dehydrogenase showed higher activity in light and may thus provide reducing power. Also for the active catabolism of citrate, a high level of isocitrate dehydrogenase is required to remove the substrate isocitrate because it would otherwise be converted to citrate by the reversible aconitase reaction. Hence, the decreased activity of isocitrate dehydrogenase in light should cause citrate to accumulate and consequently provide the building blocks for lipid and carotenogensis (Ram et al. 1984).

Indirect hints as to a light-dependent regulation of membrane fatty acid composition come from several reports on circadian regulation (which can be phaseshifted by light) in N. crassa (Cote and Brody 1987). Further, effects of supplementation of cultivation media with saturated (Mattern and Brody 1979) or unsaturated (Brody and Martins 1979) fatty acids on period length in $N$. crassa have been reported. However, also the levels of linoleic and linolenic acid in $N$. crassa mycelia oscillate, which could be caused by cyclic (de)activation or biosynthesis/degradation of a desaturase. The phase of these circadian oscillations can be light-set in a similar manner as it is the case for conidiation. Nevertheless, the oscillations in fatty acid composition are largely independent of the developmental events leading to conidiation (Roeder et al. 1982). In A. nidulans, a desaturase, encoded by ode $A$, has been deleted, and clear effects on fatty acid composition and sporulation have been observed. Additionally, it has been shown that also in this fungus, fatty acid composition is influenced by light as well as by velvet (veA) (Calvo 2008; Calvo et al. 2001).

In T. viride, lipid accumulation after photoinduction has been investigated, and significant differences were found in sporulating, photoinduced, and nonsporulating, noninduced mycelia. However, in this case, it is not possible to decide whether this effect is due to the light pulse or connected to sporulation (Betina and Koman 1980).

Nucleotide and nucleoside metabolism

Despite the importance of nucleotides and nucleosides for the fungal cell in energy metabolism and adjustment of redox potential, knowledge on their regulation in response to light in fungi is limited. NAD+ kinase is one of the key enzymes in regulation of relative levels of anabolic and catabolic pathways in the cell. In N. crassa, specific activity of NAD+ kinase increases only minutes after illumination up to twofold (Afanasieva et al. 1982). This activation can be viewed as one step of a coordinated regulatory mechanism for the activity of enzymes involved in formation and reduction of NADP and consequently in regulation of the pentose phosphate shunt (Afanasieva et al. 1982). Moreover, both activities of NADH reductase and NADH oxidase (as well as several other enzymes involved in respiration) are negatively influenced by light not only in wild-type but also in albino strains (Ramadan-Talib and Prebble 1978) of $N$. crassa. Yet, a generally negative effect of light on respiration is contradicted by the finding of an "oxidative burst", lasting about $10 \mathrm{~min}$ after onset of illumination, during which an increase in the rate of oxygen consumption has been observed in T. reesei (Farkas et al. 1990).

In $B$. emersonii, growth in light causes the nucleic acid content of the cells to increase more rapidly than in darkness and to reach a $28 \%$ higher final quantity of nucleic acids than dark-grown cells (Goldstein and Cantino 1962). Interestingly, also circadian rhythms of nucleic acid content and biosynthesis occur in $N$. crassa with a period of about $24 \mathrm{~h}$ and also in many other organisms (Martens and Sargent 1974). Since this reflects a daily rhythm which normally can be reset by light pulses, the detection of a circadian rhythm supports the finding of an influence of light on nucleotide metabolism.

\section{$c A M P$}

Cyclic adenosine monophosphate (cAMP) is a secondary messenger in eukaryotes. This compound is produced in response to several extracellular stimuli and regulates a variety of physiological processes. Two enzymes are the major regulators of cAMP levels in fungi: the biosynthetic enzyme adenylyl cyclase and the degradative phosphodiesterase (D'souza and Heitman 2001). Light pulses significantly impact cAMP levels in T. viride (Farkas et al. 1985; Gresik et al. 1988). Thereby, illumination causes rapid but transient increase in intracellular concentrations of ATP and cAMP, which might contribute to phosphorylation of 
proteins in response to light. With respect to phosphorylation, the effect of light can be substituted by addition of 3 mM cAMP (Gresik et al. 1989). These cAMP levels could be adjusted by the membrane associated adenylyl cyclase, which is activated by light - in contrast to $3^{\prime} 5^{\prime}$ cyclic AMP phosphodiesterase, for which this is not the case (Kolarova et al. 1992). In N. crassa in contrast, no alterations of cAMP levels were detected in response to light (Shaw and Harding 1987). For A. nidulans, however, photoregulation of phosphodiesterase has been reported (Gradisnik-Grapulin and Legisa 1997). In T. atroviride, a connection between the cAMP-dependent protein kinase A (PKA) and blue light perception has been drawn. PKA activity increases not only in illuminated cell extracts of the wild-type strain but also in mutants of the photoreceptors BLR-1 and BLR-2 (Casas-Flores et al. 2006). Since these strains show severely perturbed light response, this phenomenon could be due to adenylyl cyclase activated directly (or at least without participation of these photoreceptors) by light. A connection between cAMP levels and accumulation of carotenoids has been suggested in $N$. crassa in that a transient decrease of cAMP levels occurred after photoinduction of carotenoid syntheses during its lag period (Kritsky et al. 1982).

Interestingly, indications for an interconnection between cAMP levels and expression of extracellular enzymes have been detected: In Cryptococcus albidus, xylanase production can be increased by addition of exogenous cAMP (Morosoli et al. 1989). A connection of cAMP metabolism to carbon metabolism is also obvious in a more prominent cellulase producer: Prior to the onset of cellulase biosynthesis, a rise in intracellular cAMP and at the same time a decrease in the intracellular concentration of glucose-6phosphate can be observed in T. reesei (Farkas et al. 1987, 1990). In agreement with these data, cellulase formation can be enhanced by addition of cAMP, but on the other hand, enhanced levels of cAMP were not sufficient to induce cellulase gene expression in the absence of an inducer (Sestak and Farkas 1993).

This interrelationship between cAMP metabolism and expression of extracellular hydrolytic enzymes may be one mechanism contributing to light-modulated cellulase gene transcription in T. reesei (Schmoll et al. 2005). With this fungus, several steps of the signaling cascade targeting cellulase gene expression have already been elucidated. With respect to cAMP metabolism, the heterotrimeric Gprotein GNA3, a G-alpha subunit (Schmoll et al. 2009), plays an important role. Transcript abundance of this signaling factor is increased in response to light and negatively regulated by ENVOY (Schmoll et al. 2005). GNA3 significantly influences cAMP levels and strongly enhances cellulase gene expression, but only in the presence of an inducer (which is also in agreement with data on cAMP; Sestak and Farkas 1993). Intriguingly, any effects on cellulase gene expression exerted by GNA3 were only detected in light, and the activity of this G-protein seems to be modulated by an RGS protein. Also, while cAMP seems to play an important role in this regulation, additional regulatory processes are likely to be involved (Schmoll et al. 2009). Due to the numerous pathways impacted by cAMP as well as heterotrimeric G-protein signaling, a widespread and light-dependent regulatory function can also be assumed for further pathways not studied yet.

\section{Amino acid metabolism}

Being the building blocks of proteins, for which significant alterations in both quality and quantity have been shown in response to light, also the abundance of amino acids is likely to be adjusted to the different requirements for protein production as well as other functions upon illumination. As is the case for glucose, in A. ornatus, also the uptake of many amino acids was clearly decreased upon cultivation in light, but the uptake of lysine on the other hand even increased (Hill 1976). In P. blakesleeanus, illumination of dark-adapted cultures decreased ornithine decarboxylase activity (Lapointe and Cohen 1983). In the basidiomycete Polyporus hispidus, the cinnamate pathway leading from phenylalanine to hispidin is regulated by light: Nonoxidative deamination of phenylalanine to cinnamic acid is considerably higher in light-grown mycelia than in the dark. In contrast to phenylalanine ammonia lyase, tyrosine ammonia-lyase activity was increased upon growth in the dark (Nambudiri et al. 1973).

Activity of glutamic acid decarboxylase, which catalyses alpha-decarboxylation of L-glutamic acid forming gammaamino butyric acid (GABA), is stimulated by light (Pokorny et al. 2005; Strigacova et al. 2001) in T. viride. This reaction belongs to the metabolic pathway called GABA shunt (Schmit and Brody 1975) and provides energy for conidia needed to survive and germinate. In support of these findings, GABA content in mycelia of Monascus pilosus is also remarkably enhanced after illumination (Miyake et al. 2005).

Nitrogen and sulfur metabolism

For nitrogen metabolism, only a few hints as to an influence of light are available. However, the fact that nitrogen limitation leads to the differentiation of hyphae into female organs, the protoperithecia (Ricci et al. 1991; Sommer et al. 1987), and that once induced by nitrogen deprivation, the formation of protoperithecia is strongly enhanced by blue light (Innocenti et al. 1983; Sommer et al. 1987), suggesting that a connection between light response 
and nitrogen metabolism may exist. Also, it has been reported that several blue light-regulated genes are also regulated by nitrogen limitation (Sokolovsky et al. 1992) and that among the genes controlled by the circadian clock, there are several genes involved in nitrogen metabolism (Correa et al. 2003). A further indication of an involvement of a light signal could be that the oscillations of nitrate reductase activity are phase-advanced in light as compared to darkness (Christensen et al. 2004). Additionally, in $N$. crassa, nitrate reductase activity decreases, and the activity of its small subunit increases upon blue light induction (Klemm and Ninnemann 1979). Taken together, these reports arouse suspicion that light could also influence nitrogen metabolism, but there is clearly more experimental support needed to evaluate this hypothesis.

With respect to light response, also sulfur metabolism still requires elucidation. Although this metabolic pathway is well studied in fungi (Marzluf 1997), only one study dealt with an influence of light on sulfur metabolism. For T. reesei, a connection between sulfur metabolism and cellulase gene expression was detected, which is dependent on illumination. Also, uptake of sulfate by this fungus seems to be modulated in response to light (Gremel et al. 2008). A further interesting issue of this study is that there are obviously differences in light response between growth in the presence of the sulfur sources sulfate or methionine, which suggest that the presence of methionine in the medium is not only of relevance as sulfur source but also represents a signal of significant light-dependent influence on cellulase gene expression. Consequently, this interrelationship of sulfur metabolism with carbon metabolism as well as light response opens a new complex regulatory network which warrants further investigations.

\section{Secondary metabolism}

The evolutionary success of fungi on our planet is not only due to their versatile metabolism and their ability to adapt to diverse environmental conditions but also to their efficiency in chemical warfare. Fungi secrete compounds that help them compete with other microorganisms, which are not only beneficial for the fungus but, for example as antibiotics or mycotoxins, are also of crucial importance for the society (Fischer 2008; Yu and Keller 2005). Regulation of these secondary metabolites is often not only interconnected with sexual development but also with light response.

Gibberellic acid, which is the most abundant gibberellin that G. fujikuroi synthesizes, and carotenoids (which are significantly regulated by light) are both biosynthesized by the isoprenoid pathway from hydroxymethylglutaryl coenzyme A via mevalonic acid, isopentenyl diphosphate, geranyl diphosphate, farnesyl dephosphate, and geranylgeranyl diphosphate (GGDP). The pathway branches from the general terpene biosynthetic pathway at GGDP, which is a precursor of both compounds (Tudzynski 1999). There is a relationship between the biosynthesis of gibberellins and carotenoids. Increases in carotenoid production have been found to be accompanied by decreases in gibberellin production in mutants defective for carotenogenesis (Candau et al. 1991). Studying carotenogenesis in G. fujikuroi-also a watersoluble red pigment, presumably a bikaverin - was detected (Linnemannstons et al. 2002). Instead of being accumulated within the cell, it is secreted into the culture medium. Biosynthesis of this pigment parallels carotenoid biosynthesis and is also light inducible (Garbayo et al. 2003).

Production of aflatoxin in Aspergillus flavus has been shown to be negatively influenced by light already 40 years ago (Joffe and Lisker 1969). For A. alternata, an inhibitory effect of light on production of the mycotoxins alternariol and alternariol monomethyl ether has been found (Haggblom and Unestam 1979; Soderhall et al. 1978). On the contrary, another study reports that aflatoxin B1 and ochratoxin 1 production by A. flavus or Aspergillus ochraceus, respectively, is enhanced upon cultivation in light (Aziz and Moussa 1997), and except for the influence of enhanced growth, the photoperiod has no effect on specific ochratoxin production under field conditions (Belli et al. 2006). In addition to aflatoxin, production of averufin and versicolorin $\mathrm{A}$ and $\mathrm{C}$ is regulated in response to light in Aspergillus parasiticus as well. Interestingly, this regulation is dependent on the temperature. All these compounds are synthesized by a polyketide pathway, and therefore, an impact of light on the whole pathway could be assumed (Bennett et al. 1981). However, 25 genes involved in aflatoxin biosynthesis and regulation are clustered (Yu et al. 2004), and those responsible for integration of the light signal into this cascade remain to be determined. Elucidation of the potential roles of these genes in light response (and possibly response to other interfering environmental cues) of aflatoxin production may also help to clarify how conflicting results for light regulation of aflatoxin production could have occurred.

Although the physiological meaning of light dependent regulation of secondary metabolism remains to be determined, considerable progress has also been made in elucidation of the underlying mechanisms (Bayram et al. 2008b, 2009; Fox and Howlett 2008; Purschwitz et al. 2009). Interestingly, intracellular cAMP levels mediate a PKA-dependent regulatory influence on aflatoxin synthesis in Aspergillus spp. and FadA (a G-protein alpha subunit)/ PKA regulate toxin synthesis (Roze et al. 2004). Although a connection of this regulatory mechanism to light response has not yet been shown, data on light regulation of cAMP levels, G-protein signaling, and PKA-dependent regulation in other fungi (see above) suggest that this pathway plays a role in light-modulated aflatoxin biosynthesis. 
While aflatoxin is one of the most prominent mycotoxins, also for toxins of other fungi, a regulatory influence of light has been detected. The polyketide phytotoxin cercosporin is produced by many Cercospora spp. and generates reactive oxygen species. Light is an essential inducer for cercosporin biosynthesis and absolutely necessary for cercosporin toxicity (Daub et al. 2005). Signaling and subsequent regulation of cercosporin production in response to numerous environmental cues are suggested to involve $\mathrm{Ca} 2+1$ calmodulin signaling, mitogen-activated protein kinase signaling, and G-protein signaling (You et al. 2008 and references therein). Similarly, an interrelationship with Gprotein and PKA signaling has been observed for the peptaibol atroviridin produced by $H$. atroviridis and was shown to be dependent on the function of the blue light regulators BLR1 and BLR2, as could be expected from the influence of light on its biosynthesis (Komon-Zelazowska et al. 2007; Kubicek et al. 2007). Also, a role of VeA in mycotoxin production has been shown in Fusarium verticillioides (Myung et al. 2009), A. nidulans (Kato et al. 2003), A. parasiticus (Calvo et al. 2004), and A. flavus (Duran et al. 2007).

In contrast to the production of mycotoxins by fungi, many other secondary metabolites are of high industrial value because of their applications as antibiotics or food production. One fungus which is used for production of traditional oriental food is Monascus. This fungus produces both beneficial secondary metabolites and the polyketide mycotoxin citrinin (Blanc et al. 1995). Interestingly, the stimulatory effect of red light on production of these compounds is more pronounced than that of blue light, which only stimulates production of GABA, but not that of the other metabolites (Miyake et al. 2005).

With respect to pharmaceutical use, penicillin is one of the most important secondary metabolites to date. In accordance with several other secondary metabolites discussed above, also the biosynthesis of penicillin is inhibited in light. One crucial factor regulating penicillin production in Aspergillus is VeA, which acts on the respective pathway via regulation of the acvA gene (Sprote and Brakhage 2007). A homolog of another important signaling component shown to be connected to the light response pathway, protein kinase C (Franchi et al. 2005), has been implicated in regulation of localization of AnBH1, a repressor of penicillin biosynthesis in A. nidulans (Herrmann et al. 2006), albeit light-related phenomena have not been investigated in the respective study.

\section{Conclusions and outlook}

In summary, the significance of the daily environmental changes brought about by the rotation of earth is clearly reflected in the metabolic reactions of fungi to these conditions. Literally, every important pathway is adjusted to the requirements of protection from light and/or the preparations for reproduction, the regulation of which is closely connected to light signaling. Although the metabolic effects outlined in this review represent a patchwork of data obtained with numerous fungi, the bottom line is still valid: In many cases, the output of a light effect is similar in different species; nevertheless, the regulatory mechanisms causing the respective effect are much less conserved. Therefore, a light effect detected in one species can neither be taken for granted not be ruled out in another without experimental confirmation.

The obvious adaptations to day and night imply on the one hand that a more detailed understanding of the underlying regulatory mechanism not only will increase our knowledge of physiology of fungi but can also help to enhance biotechnological processes. Manipulation of key genes (once identified) could abolish negative regulation of a given mechanism or enhance expression of certain genes without the need of a light stimulus.

On the other hand, the broad regulatory impact of light on virtually all important metabolic pathways suggests that the random light pulses, which are unavoidable with conventional cultivations and subsequent analysis of fungi, may seriously jeopardize reproducibility and validity of data. Therefore, caution is advisable with results obtained under uncontrolled light regimes. Especially regulatory genes and genes involved in signal transduction often show a significant transcriptional response to light within minutes. Although particularly those fungi applied in biotechnology have been cultivated and maintained under laboratory conditions for decades in some cases, their evolutionary-acquired features persist and should be considered with experimental design in order to make sure that the data obtained indeed reflect the physiological condition of the organism.

Acknowledgments MS is recipient of an APART fellowship (No. 11212) of the Austrian Academy of Sciences at the Institute of Chemical Engineering, TU Vienna. DT is recipient of a DOC fFORTE fellowship (No. 22348) of the Austrian Academy of Sciences at the Institute of Chemical Engineering, TU Vienna. This work was supported by a grant of the Austria Science Fund (FWF; P21072) to MS.

Open Access This article is distributed under the terms of the Creative Commons Attribution Noncommercial License which permits any noncommercial use, distribution, and reproduction in any medium, provided the original author(s) and source are credited.

\section{References}

Afanasieva TP, Filippovich S, Sokolovsky V, Kritsky MS (1982) Developmental regulation of NAD + kinase in Neurospora crassa. Arch Microbiol 133:307-311 
Almeida ER, Cerda-Olmedo E (2008) Gene expression in the regulation of carotene biosynthesis in Phycomyces. Curr Genet 53:129-137

Arpaia G, Cerri F, Baima S, Macino G (1999) Involvement of protein kinase $\mathrm{C}$ in the response of Neurospora crassa to blue light. Mol Gen Genet 262:314-322

Assante G, Merlini L, Nasini G (1977) (+)-Abscisic acid, a metabolite of the fungus Cercospora rosicola. Cell Mol Life Sci 33:15561557

Avalos J, Cerdà-Olmedo E (1987) Carotenoid mutants of Gibberella fujikuroi. Curr Genet 11:505-511

Avalos J, Cerda-Olmedo E (2004) Fungal carotenoid production. In: Arora DK, Bridge PD, Bhatnagar D (eds) Handbook of fungal biotechnology. Marcel Dekker, New York, pp 367-378

Avalos J, Schrott EL (1990) Photoinduction of carotenoid biosynthesis in Gibberella fujikuroi. FEMS Microbiol Lett 66:295-298

Avalos J, Bejarano ER, Cerda-Olmedo E (1993) Photoinduction of carotenoid biosynthesis. Methods Enzymol 214:283-294

Avery PB, Faull J, Simmonds MS (2004) Effect of different photoperiods on the growth, infectivity and colonization of Trinidadian strains of Paecilomyces fumosoroseus on the greenhouse whitefly, Trialeurodes vaporariorum, using a glass slide bioassay. J Insect Sci 4:38

Aziz NH, Moussa LA (1997) Influence of white light, near-UV irradiation and other environmental conditions on production of aflatoxin B1 by Aspergillus flavus and ochratoxin A by Aspergillus ochraceus. Nahrung 41:150-154

Ballario P, Vittorioso P, Magrelli A, Talora C, Cabibbo A, Macino G (1996) White collar-1, a central regulator of blue light responses in Neurospora, is a zinc finger protein. EMBO J 15:1650-1657

Banno S, Ochiai N, Noguchi R, Kimura M, Yamaguchi I, Kanzaki S, Murayama T, Fujimura M (2005) A catalytic subunit of cyclic AMP-dependent protein kinase, PKAC-1, regulates asexual differentiation in Neurospora crassa. Genes Genet Syst 80:25-34

Bayram O, Biesemann C, Krappmann S, Galland P, Braus GH (2008a) More than a repair enzyme: Aspergillus nidulans photolyase-like CryA is a regulator of sexual development. Mol Biol Cell 19:3254-3262

Bayram O, Krappmann S, Ni M, Bok JW, Helmstaedt K, Valerius O, Braus-Stromeyer S, Kwon NJ, Keller NP, Yu JH, Braus GH (2008b) $\mathrm{VelB} / \mathrm{VeA} / \mathrm{LaeA}$ complex coordinates light signal with fungal development and secondary metabolism. Science 320:1504-1506

Bayram O, Sari F, Braus GH, Irniger S (2009) The protein kinase ImeB is required for light-mediated inhibition of sexual development and for mycotoxin production in Aspergillus nidulans. Mol Microbiol 71:1278-1295

Bejarano ER, Avalos J, Lipson ED, Cerdá-Olmedo E (1991) Photoinduced accumulation of carotene in Phycomyces. Planta 183:1-9

Belli N, Ramos AJ, Sanchis V, Marin S (2006) Effect of photoperiod and day-night temperatures simulating field conditions on growth and ochratoxin A production of Aspergillus carbonarius strains isolated from grapes. Food Microbiol 23:622-627

Bennett JW, Dunn JJ, Goldsman CI (1981) Influence of white light on production of aflatoxins and anthraquinones in Aspergillus parasiticus. Appl Environ Microbiol 41:488-491

Bergman K, Burke PV, Cerda-Olmedo E, David CN, Delbruck M, Foster KW, Goodell EW, Heisenberg M, Meissner G, Zalokar M, Dennison DS, Shropshire W Jr (1969) Phycomyces. Microbiol Mol Biol Rev 33:99-157

Berrocal-Tito GM, Esquivel-Naranjo EU, Horwitz BA, HerreraEstrella A (2007) Trichoderma atroviride PHR1, a fungal photolyase responsible for DNA repair, autoregulates its own photoinduction. Eukaryot Cell 6:1682-1692

Betina V, Koman V (1980) Changes in the lipid composition during the photo-induced conidiation of Trichoderma viride. Folia Microbiol (Praha) 25:295-300
Betina V, Zajacova J (1978) Regulation of periodicity and intensity of photo-induced conidiation of Trichoderma viride. Folia Microbiol (Praha) 23:453-459

Bieszke JA, Li L, Borkovich KA (2007) The fungal opsin gene nop-1 is negatively-regulated by a component of the blue light sensing pathway and influences conidiation-specific gene expression in Neurospora crassa. Curr Genet 52:149-157

Blanc PJ, Laussac JP, Le Bars J, Le Bars P, Loret MO, Pareilleux A, Prome D, Prome JC, Santerre AL, Goma G (1995) Characterization of monascidin A from Monascus as citrinin. Int J Food Microbiol 27:201-213

Blasco JL, Roeßink D, Iturriaga EA, Eslava AP, Galland P (2001) Photocarotenogenesis in Phycomyces: expression of the carB gene encoding phytoene dehydrogenase. J Plant Res 114:25-31

Bluhm BH, Dunkle LD (2008) PHL1 of Cercospora zeae-maydis encodes a member of the photolyase/cryptochrome family involved in UV protection and fungal development. Fungal Genet Biol 45:1364-1372

Britton G, Liaaen-Jensen S, Pfander H (1998) Carotenoids. Birkhäuser, Basel

Brody S, Martins SA (1979) Circadian rhythms in Neurospora crassa: effects of unsaturated fatty acids. J Bacteriol 137:912-915

Brunner M, Kaldi K (2008) Interlocked feedback loops of the circadian clock of Neurospora crassa. Mol Microbiol 68:255-262

Bünning E (1973) The physiological clock, revised third edition. Springer, New York

Busch S, Eckert SE, Krappmann S, Braus GH (2003) The COP9 signalosome is an essential regulator of development in the filamentous fungus Aspergillus nidulans. Mol Microbiol 49:717730

Calvo AM (2008) The VeA regulatory system and its role in morphological and chemical development in fungi. Fungal Genet Biol 45:1053-1061

Calvo AM, Gardner HW, Keller NP (2001) Genetic connection between fatty acid metabolism and sporulation in Aspergillus nidulans. J Biol Chem 276:25766-25774

Calvo AM, Bok J, Brooks W, Keller NP (2004) veA is required for toxin and sclerotial production in Aspergillus parasiticus. Appl Environ Microbiol 70:4733-4739

Candau R, Avalos J, Cerda-Olmedo E (1991) Gibberellins and carotenoids in the wild type and mutants of Gibberella fujikuroi. Appl Environ Microbiol 57:3378-3382

Carlile MJ (1965) The photobiology of fungi. Annu Rev Plant Physiol $16: 175-202$

Casas-Flores S, Rios-Momberg M, Rosales-Saavedra T, MartinezHernandez P, Olmedo-Monfil V, Herrera-Estrella A (2006) Cross talk between a fungal blue-light perception system and the cyclic AMP signaling pathway. Eukaryot Cell 5:499-506

Cerda-Olmedo E (2001) Phycomyces and the biology of light and color. FEMS Microbiol Rev 25:503-512

Chen CH, Ringelberg CS, Gross RH, Dunlap JC, Loros JJ (2009) Genome-wide analysis of light-inducible responses reveals hierarchical light signalling in Neurospora. EMBO J 28:10291042

Christensen MK, Falkeid G, Loros JJ, Dunlap JC, Lillo C, Ruoff P (2004) A nitrate-induced frq-less oscillator in Neurospora crassa. J Biol Rhythms 19:280-286

Correa A, Lewis ZA, Greene AV, March IJ, Gomer RH, Bell-Pedersen D (2003) Multiple oscillators regulate circadian gene expression in Neurospora. Proc Natl Acad Sci USA 100:13597-13602

Corrochano LM (2007) Fungal photoreceptors: sensory molecules for fungal development and behaviour. Photochem Photobiol Sci 6:725-736

Cote GG, Brody S (1987) Circadian rhythms in Neurospora crassa: a clock mutant, prd-1, is altered in membrane fatty acid composition. Biochim Biophys Acta 904:131-139 
Crosson S, Moffat K (2002) Photoexcited structure of a plant photoreceptor domain reveals a light-driven molecular switch. Plant Cell 14:1067-1075

Crosson S, Rajagopal S, Moffat K (2003) The LOV domain family: photoresponsive signaling modules coupled to diverse output domains. Biochemistry 42:2-10

Crosthwaite SK, Dunlap JC, Loros JJ (1997) Neurospora wc-1 and $w c-2$ : transcription, photoresponses, and the origins of circadian rhythmicity. Science 276:763-769

Daub ME, Herrero S, Chung KR (2005) Photoactivated perylenequinone toxins in fungal pathogenesis of plants. FEMS Microbiol Lett 252:197-206

Devlin PF (2002) Signs of the time: environmental input to the circadian clock. J Exp Bot 53:1535-1550

Dobzhansky T (1973) Nothing in biology makes sense except in the light of evolution. Am Biol Teach 35:125-129

Dong W, Tang X, Yu Y, Nilsen R, Kim R, Griffith J, Arnold J, Schuttler HB (2008) Systems biology of the clock in Neurospora crassa. PLoS ONE 3:e3105

Dreyer J, Eichhorn H, Friedlin E, Kurnsteiner H, Kuck U (2007) A homologue of the Aspergillus velvet gene regulates both cephalosporin $\mathrm{C}$ biosynthesis and hyphal fragmentation in Acremonium chrysogenum. Appl Environ Microbiol 73:3412-3422

D'Souza CA, Heitman J (2001) Conserved cAMP signaling cascades regulate fungal development and virulence. FEMS Microbiol Rev 25:349-364

Dunlap JC, Loros JJ (2004) The Neurospora circadian system. J Biol Rhythms 19:414-424

Dunlap JC, Loros JJ, Colot HV, Mehra A, Belden WJ, Shi M, Hong CI, Larrondo LF, Baker CL, Chen CH, Schwerdtfeger C, Collopy PD, Gamsby JJ, Lambreghts R (2007) A circadian clock in Neurospora: how genes and proteins cooperate to produce a sustained, entrainable, and compensated biological oscillator with a period of about a day. Cold Spring Harb Symp Quant Biol 72:57-68

Duran RM, Cary JW, Calvo AM (2007) Production of cyclopiazonic acid, aflatrem, and aflatoxin by Aspergillus flavus is regulated by $v e A$, a gene necessary for sclerotial formation. Appl Microbiol Biotechnol 73:1158-1168

Ehrenshaft M, Upchurch RG (1991) Isolation of light-enhanced cDNAs of Cercospora kikuchii. Appl Environ Microbiol 57:2671-2676

Elvin M, Loros JJ, Dunlap JC, Heintzen C (2005) The PAS/LOV protein VIVID supports a rapidly dampened daytime oscillator that facilitates entrainment of the Neurospora circadian clock. Genes Dev 19:2593-2605

Estrada AF, Avalos J (2008) The White Collar protein WcoA of Fusarium fujikuroi is not essential for photocarotenogenesis, but is involved in the regulation of secondary metabolism and conidiation. Fungal Genet Biol 45:705-718

Farkas V, Sulova Z, Lehotsky J (1985) Effect of light on the concentration of adenine nucleotides in Trichoderma viride. $\mathrm{J}$ Gen Microbiol 131:317-320

Farkas V, Sesták S, Gresik M, Kolarova N, Labudová I, Bauer S (1987) Induction of cellulase in Trichoderma reesei grown on lactose. Acta Biotechnol 7:425-429

Farkas V, Gresik M, Kolarova N, Sulova Z, Sestak S (1990) Biochemical and physiological changes during photoinduced conidiation and derepression of cellulase synthesis in Trichoderma. In: Kubicek CP, Eveleigh DE, Esterbauer H, Steiner W, Kubicek-Pranz EM (eds) Trichoderma reesei cellulase: biochemistry, genetics, physiology and application. Graham, Cambridge, pp 139-155

Fiema J (1983) Some aspects of nitrogen metabolism in Aspergillus giganteus mut. alba. I. Chitin content in the cell walls. Acta Physiol Plant 5:113-121
Fiema J (1993) The effect of light and glucose concentration on the content of S- and R-glucans in the mycelium of Aspergillus giganteus mut. alba. J Basic Microbiol 33:3-8

Fiema J, Golbiewska T (1981) Chitin synthesis during growth of Aspergillus giganteus mut alba in light and darkness. Acta Biol Crac 23:1-6

Fiema J, Zurzycka A, Bruneteau M (1991) Glucans in the mycelium of Aspergillus giganteus mut. alba: alkali-soluble glucans. J Basic Microbiol 31:37-42

Fischer R (2008) Developmental biology. Sex and poison in the dark. Science 320:1430-1431

Fox EM, Howlett BJ (2008) Secondary metabolism: regulation and role in fungal biology. Curr Opin Microbiol 11:481-487

Franchi L, Fulci V, Macino G (2005) Protein kinase C modulates light responses in Neurospora by regulating the blue light photoreceptor WC-1. Mol Microbiol 56:334-345

Friedl MA, Kubicek CP, Druzhinina IS (2008a) Carbon source dependence and photostimulation of conidiation in Hypocrea atroviridis. Appl Environ Microbiol 74:245-250

Friedl MA, Schmoll M, Kubicek CP, Druzhinina IS (2008b) Photostimulation of Hypocrea atroviridis growth occurs due to a crosstalk of carbon metabolism, blue light receptors and response to oxidative stress. Microbiology 154:1229-1241

Garbayo I, Vílchez C, Nava-Saucedo JE, Barbotin JN (2003) Nitrogen, carbon and light-mediated regulation studies of carotenoid biosynthesis in immobilized mycelia of Gibberella fujikuroi. Enzyme Microb Technol 33:629-634

Garce's R, Medina JR (1985) Light-dependent decrease in alcohol dehydrogenase activity of Phycomyces. Exp Mycol 9:94-98

Garton GA, Goodwin TW, Lijinsky W (1951) Studies in carotenogenesis; general conditions governing beta-carotene synthesis by the fungus Phycomyces blakesleeanus Burgeff. Biochem J 48:154-163

Goldman GH, Geremia RA, Caplan AB, Vila SB, Villarroel R, Van Montagu M, Herrera-Estrella A (1992) Molecular characterization and regulation of the phosphoglycerate kinase gene from Trichoderma viride. Mol Microbiol 6:1231-1242

Goldstein A, Cantino EC (1962) Light-stimulated polysaccharide and protein synthesis by synchronized, single generations of Blastocladiella emersonii. J Gen Microbiol 28:689-699

Goodrich-Tanrikulu M, Howe K, Stafford A, Nelson MA (1998) Changes in fatty acid composition of Neurospora crassa accompany sexual development and ascospore germination. Microbiology 144(Pt 7):1713-1720

Graafmans WDJ (1974) Metabolism in Penicillium isariiforme on exposure to light, with special reference to citric acid synthesis. J Gen Microbiol 82:247-252

Graafmans WDJ (1976) Enige biochemische aspecten van de morfogenese bij Penicillium isariiforme. Ph.D. thesis, University of Amsterdam

Graafmans WDJ (1977) Effect of blue light on metabolism in Penicillium isariiforme. J Gen Microbiol 101:157-161

Gradisnik-Grapulin M, Legisa M (1997) A spontaneous change in the intracellular cyclic AMP level in Aspergillus niger is influenced by the sucrose concentration in the medium and by light. Appl Environ Microbiol 63:2844-2849

Greene AV, Keller N, Haas H, Bell-Pedersen D (2003) A circadian oscillator in Aspergillus spp. regulates daily development and gene expression. Eukaryot Cell 2:231-237

Gremel G, Dorrer M, Schmoll M (2008) Sulphur metabolism and cellulase gene expression are connected processes in the filamentous fungus Hypocrea jecorina (anamorph Trichoderma reesei). BMC Microbiol 8:174

Gresik M, Kolarova N, Farkas V (1988) Membrane potential, ATP, and cyclic AMP changes induced by light in Trichoderma viride. Exp Mycol 12:295-301 
Gresik M, Kolarova N, Farkas V (1989) Light-stimulated phosphorylation of proteins in cell-free extracts from Trichoderma viride. FEBS Lett 248:185-187

Gresik M, Kolarova N, Farkas V (1991) Hyperpolarization and intracellular acidification in Trichoderma viride as a response to illumination. J Gen Microbiol 137:2605-2609

Gubler F, Millar AA, Jacobsen JV (2005) Dormancy release, ABA and pre-harvest sprouting. Curr Opin Plant Biol 8:183-187

Haggblom P, Unestam T (1979) Blue light inhibits mycotoxin production and increases total lipids and pigmentation in Alternaria alternata. Appl Environ Microbiol 38:1074-1077

Halaban R (1975) Glucose transport-deficient mutant of Neurospora crassa with an unusual rhythmic growth pattern. J Bacteriol 121:1056-1063

Harding RW, Huang PC, Mitchell HK (1969) Photochemical studies of the carotenoid biosynthetic pathway in Neurospora crassa. Arch Biochem Biophys 129:696-707

Harper SM, Neil LC, Gardner KH (2003) Structural basis of a phototropin light switch. Science 301:1541-1544

Heintzen C, Liu Y (2007) The Neurospora crassa circadian clock. Adv Genet 58:25-66

Heintzen C, Loros JJ, Dunlap JC (2001) The PAS protein VIVID defines a clock-associated feedback loop that represses light input, modulates gating, and regulates clock resetting. Cell 104:453-464

Herrera-Estrella A, Horwitz BA (2007) Looking through the eyes of fungi: molecular genetics of photoreception. Mol Microbiol 64:5-15

Herrera-Estrella L, Ruiz-Herrera J (1983) Light response in Phycomyces blakesleeanus: evidence for roles of chitin biosynthesis and breakdown. Exp Mycol 7:362-369

Herrmann M, Sprote P, Brakhage AA (2006) Protein kinase C (PkcA) of Aspergillus nidulans is involved in penicillin production. Appl Environ Microbiol 72:2957-2970

Hill EP (1976) Effect of light on growth and sporulation of Aspergillus ornatus. J Gen Microbiol 95:39-44

Huang G, Chen S, Li S, Cha J, Long C, Li L, He Q, Liu Y (2007) Protein kinase $\mathrm{A}$ and casein kinases mediate sequential phosphorylation events in the circadian negative feedback loop. Genes Dev 21:3283-3295

Idnurm A, Heitman J (2005) Light controls growth and development via a conserved pathway in the fungal kingdom. PLoS Biol 3:e95

Idnurm A, Rodriguez-Romero J, Corrochano LM, Sanz C, Iturriaga EA, Eslava AP, Heitman J (2006) The Phycomyces madA gene encodes a blue-light photoreceptor for phototropism and other light responses. Proc Natl Acad Sci USA 103:4546-4551

Iigusa H, Yoshida Y, Hasunuma K (2005) Oxygen and hydrogen peroxide enhance light-induced carotenoid synthesis in Neurospora crassa. FEBS Lett 579:4012-4016

Innocenti FD, Pohl U, Russo VE (1983) Photoinduction of protoperithecia in Neurospora crassa by blue light. Photochem Photobiol 37:49-51

Jayaram M, Presti D, Delbrück M (1979) Light-induced carotene synthesis in Phycomyces. Exp Mycol 3:42-52

Jeong HY, Song MH, Back JH, Han DM, Wu X, Monnier V, Jahng KY, Chae KS (2002) The veA gene is necessary for the inducible expression by fructosyl amines of the Aspergillus nidulans faoA gene encoding fructosyl amino acid oxidase (amadoriase, EC 1.5.3). Arch Microbiol 178:344-350

Jeong HY, Kim H, Han DM, Jahng KY, Chae KS (2003) Expression of the mnpA gene that encodes the mannoprotein of Aspergillus nidulans is dependent on fadA and $f l b A$ as well as veA. Fungal Genet Biol 38:228-236

Joffe AZ, Lisker N (1969) Effects of light, temperature, and $\mathrm{pH}$ value on aflatoxin production in vitro. Appl Microbiol 18:517-518

Kafer E (1965) Origins of translocations in Aspergillus nidulans. Genetics 52:217-232
Kallies A, Mohsenzadeh S, Rensing L (1992) Effects of light on protein secretion in Neurospora crassa. Arch Microbiol 157:104-106

Kato N, Brooks W, Calvo AM (2003) The expression of sterigmatocystin and penicillin genes in Aspergillus nidulans is controlled by $v e A$, a gene required for sexual development. Eukaryot Cell 2:1178-1186

Kim H, Han K, Kim K, Han D, Jahng K, Chae K (2002) The veA gene activates sexual development in Aspergillus nidulans. Fungal Genet Biol 37:72-80

Klemm E, Ninnemann H (1979) Nitrate reductase - a key enzyme in blue light-promoted conidiation and absorbance change of Neurospora. Photochem Photobiol 29:629-632

Kohl FG (1902) Untersuchungen über das Carotin und seine physiologische Bedeutung in der Pflanze. Borntraeger, Leipzig

Kolarova N, Haplova J, Gresik M (1992) Light-activated adenyl cyclase from Trichoderma viride. FEMS Microbiol Lett 72:275-278

Komon-Zelazowska M, Neuhof T, Dieckmann R, von Dohren H, Herrera-Estrella A, Kubicek CP, Druzhinina IS (2007) Formation of atroviridin by Hypocrea atroviridis is conidiation associated and positively regulated by blue light and the G protein GNA3. Eukaryot Cell 6:2332-2342

Krappmann S, Bayram O, Braus GH (2005) Deletion and allelic exchange of the Aspergillus fumigatus veA locus via a novel recyclable marker module. Eukaryot Cell 4:1298-1307

Kritsky MS, Sokolovsky VY, Belozerskaya TA, Chernysheva EK (1982) Relationship between cyclic AMP level and accumulation of carotenoid pigments in Neurospora crassa. Arch Microbiol 133:206-208

Kubicek CP, Komon-Zelazowska M, Sandor E, Druzhinina IS (2007) Facts and challenges in the understanding of the biosynthesis of peptaibols by Trichoderma. Chem Biodivers 4:1068-1082

Kuzina V, Cerda-Olmedo E (2007) Ubiquinone and carotene production in the Mucorales Blakeslea and Phycomyces. Appl Microbiol Biotechnol 76:991-999

Lakin-Thomas PL (1992) Phase resetting of the Neurospora crassa circadian oscillator: effects of inositol depletion on sensitivity to light. J Biol Rhythms 7:227-239

Lapointe DS, Cohen RJ (1983) Ornithine decarboxylase in Phycomyces: in vitro and in vivo properties. Arch Biochem Biophys 224:515-525

Lewis ZA, Correa A, Schwerdtfeger C, Link KL, Xie X, Gomer RH, Thomas T, Ebbole DJ, Bell-Pedersen D (2002) Overexpression of White Collar-1 (WC-1) activates circadian clock-associated genes, but is not sufficient to induce most light-regulated gene expression in Neurospora crassa. Mol Microbiol 45:917-931

Li S, Myung K, Guse D, Donkin B, Proctor RH, Grayburn WS, Calvo AM (2006) FvVE1 regulates filamentous growth, the ratio of microconidia to macroconidia and cell wall formation in Fusarium verticillioides. Mol Microbiol 62:1418-1432

Lin C, Todo T (2005) The cryptochromes. Genome Biol 6:220

Linden H, Macino G (1997) White collar 2, a partner in blue-light signal transduction, controlling expression of light-regulated genes in Neurospora crassa. EMBO J 16:98-109

Linnemannstons P, Schulte J, del Mar Prado M, Proctor RH, Avalos J, Tudzynski B (2002) The polyketide synthase gene pks4 from Gibberella fujikuroi encodes a key enzyme in the biosynthesis of the red pigment bikaverin. Fungal Genet Biol 37:134-148

Loros J (2005) A kinase for light and time. Mol Microbiol 56:299-302

Maheshwari R (2007) Circadian rhythm in the pink-orange bread mould Neurospora crassa: for what? J Biosci 32:1053-1058

Marsh PB, Taylor EE, Bassler LM (1959) A guide to the literature on certain effects of light on fungi: reproduction, morphology, pigmentation, and phototropic phenomena. Plant Disease Reptr Suppl 261:251-312

Martens CL, Sargent ML (1974) Circadian rhythms of nucleic acid metabolism in Neurospora crassa. J Bacteriol 117:1210-1215 
Marzluf GA (1997) Molecular genetics of sulfur assimilation in filamentous fungi and yeast. Annu Rev Microbiol 51:73-96

Mattern D, Brody S (1979) Circadian rhythms in Neurospora crassa: effects of saturated fatty acids. J Bacteriol 139:977-983

Meissner G, Delbruck M (1968) Carotenes and retinal in Phycomyces mutants. Plant Physiol 43:1279-1283

Miyake T, Mori A, Kii T, Okuno T, Usui Y, Sato F, Sammoto H, Watanabe A, Kariyama M (2005) Light effects on cell development and secondary metabolism in Monascus. J Ind Microbiol Biotechnol 32:103-108

Mooney JL, Yager LN (1990) Light is required for conidiation in Aspergillus nidulans. Genes Dev 4:1473-1482

Morosoli R, Durand S, Boucher F (1989) Stimulation of xylanase synthesis in Cryptococcus albidus by cyclic AMP. FEMS Microbiol Lett 57:57-60

Myung K, Li S, Butchko RA, Busman M, Proctor RH, Abbas HK, Calvo AM (2009) FvVE1 regulates biosynthesis of the mycotoxins fumonisins and fusarins in Fusarium verticillioides. J Agric Food Chem 57:5089-5094

Nambudiri AM, Vance CP, Towers GH (1973) Effect of light on enzymes of phenylpropanoid metabolism and hispidin biosynthesis in Polyporus hispidus. Biochem J 134:891-897

Nelson MA, Morelli G, Carattoli A, Romano N, Macino G (1989) Molecular cloning of a Neurospora crassa carotenoid biosynthetic gene (albino-3) regulated by blue light and the products of the white collar genes. Mol Cell Biol 9:1271-1276

Nemčovič M, Farkaš V (2001) Cell-wall composition and polysaccharide synthase activity changes following photoinduction in Trichoderma viride. Acta Biol Hung 52:281-288

Norman SM, Maier VP, Echols LC (1981) Influence of nitrogen source, thiamine, and light on biosynthesis of abscisic acid by Cercospora rosicola Passerini. Appl Environ Microbiol 41:981-985

Perkins DD, Radford A, Newmeyer D, Bjorkman M (1982) Chromosomal loci of Neurospora crassa. Microbiol Rev 46: 426-570

Pokorny R, Vargovic P, Holker U, Janssen M, Bend J, Hudecova D, Varecka L (2005) Developmental changes in Trichoderma viride enzymes abundant in conidia and the light-induced conidiation signalling pathway. J Basic Microbiol 45:219-229

Potapova TV, Levina NN, Belozerskaya TA, Kritsky MS, Chailakhian LM (1984) Investigation of electrophysiological responses of Neurospora crassa to blue light. Arch Microbiol 137:262-265

Purschwitz J, Muller S, Kastner C, Fischer R (2006) Seeing the rainbow: light sensing in fungi. Curr Opin Microbiol 9:566-571

Purschwitz J, Muller S, Kastner C, Schoser M, Haas H, Espeso EA, Atoui A, Calvo AM, Fischer R (2008) Functional and physical interaction of blue- and red-light sensors in Aspergillus nidulans. Curr Biol 18:255-259

Purschwitz J, Muller S, Fischer R (2009) Mapping the interaction sites of Aspergillus nidulans phytochrome FphA with the global regulator VeA and the White Collar protein LreB. Mol Genet Genomics 281:35-42

Puyesky M, Ponce-Noyola P, Horwitz BA, Herrera-Estrella A (1997) Glyceraldehyde-3-phosphate dehydrogenase expression in Trichoderma harzianum is repressed during conidiation and mycoparasitism. Microbiology 143(Pt 10):3157-3164

Quiles-Rosillo MD, Ruiz-Vazquez RM, Torres-Martinez S, Garre V (2005) Light induction of the carotenoid biosynthesis pathway in Blakeslea trispora. Fungal Genet Biol 42:141-153

Ram S, Nair BG, Chhatpar HS (1984) Photoregulation of some enzymes from Neurospora crassa. Experientia 40:1382-1384

Ramadan-Talib Z, Prebble J (1978) Photosensitivity of respiration in Neurospora mitochondria. A protective role for carotenoid. Biochem J 176:767-775

Ricci M, Krappmann D, Russo VEA (1991) Nitrogen and carbon starvation regulate conidia and protoperithecia formation of
Neurospora crassa grown on solid media. Fungal Genet Newsl 38:87-88

Rodriguez-Aparicio LB, Rua J, De Arriaga D, Soler J (1987) Lightinduced effects of several enzymes of carbohydrate metabolism in Phycomyces blakesleeanus. Int J Biochem 19:1211-1215

Rodriguez-Ortiz R, Limon MC, Avalos J (2009) Regulation of carotenogenesis and secondary metabolism by nitrogen in wildtype Fusarium fujikuroi and carotenoid-overproducing mutants. Appl Environ Microbiol 75:405-413

Rodriguez-Romero J, Corrochano LM (2004) The gene for the heatshock protein HSP100 is induced by blue light and heat-shock in the fungus Phycomyces blakesleeanus. Curr Genet 46:295-303

Roeder PE, Sargent ML, Brody S (1982) Circadian rhythms in Neurospora crassa: oscillations in fatty acids. Biochemistry 21:4909-4916

Roenneberg T, Merrow M (1999) Circadian systems and metabolism. J Biol Rhythms 14:449-459

Rosales-Saavedra T, Esquivel-Naranjo EU, Casas-Flores S, MartinezHernandez P, Ibarra-Laclette E, Cortes-Penagos C, HerreraEstrella A (2006) Novel light-regulated genes in Trichoderma atroviride: a dissection by cDNA microarrays. Microbiology 152:3305-3317

Roze LV, Beaudry RM, Keller NP, Linz JE (2004) Regulation of aflatoxin synthesis by $\mathrm{FadA} / \mathrm{cAMP} /$ protein kinase A signaling in Aspergillus parasiticus. Mycopathologia 158:219-232

Rua J, Rodriguez-Aparicio LB, Busto F, Soler J (1987) Effect of light on several metabolites of carbohydrate metabolism in Phycomyces blakesleeanus. J Bacteriol 169:904-907

Ruepp A, Zollner A, Maier D, Albermann K, Hani J, Mokrejs M, Tetko I, Guldener U, Mannhaupt G, Munsterkotter M, Mewes HW (2004) The FunCat, a functional annotation scheme for systematic classification of proteins from whole genomes. Nucleic Acids Res 32:5539-5545

Ruiz-Herrera J, Martinez-Cadena G, Valenzuela C, Reyna G (1990) Possible roles of calcium and calmodulin in the light-stimulation of wall biosynthesis in Phycomyces. Photochem Photobiol $52: 217-221$

Ruiz-Hidalgo MJ, Benito EP, Sandmann G, Eslava AP (1997) The phytoene dehydrogenase gene of Phycomyces: regulation of its expression by blue light and vitamin A. Mol Gen Genet 253:734-744

Ruiz-Roldan MC, Garre V, Guarro J, Marine M, Roncero MI (2008) Role of the white collar 1 photoreceptor in carotenogenesis, UV resistance, hydrophobicity, and virulence of Fusarium oxysporum. Eukaryot Cell 7:1227-1230

Saelices L, Youssar L, Holdermann I, Al-Babili S, Avalos J (2007) Identification of the gene responsible for torulene cleavage in the Neurospora carotenoid pathway. Mol Genet Genomics 278:527537

Sandmann G, Misawa N, Wiedemann M, Vittorioso P, Carattoli A, Morelli G, Macino G (1993) Functional identification of al-3 from Neurospora crassa as the gene for geranylgeranyl pyrophosphate synthase by complementation with $\mathrm{crt}$ genes, in vitro characterization of the gene product and mutant analysis. J Photochem Photobiol B 18:245-251

Schmidhauser TJ, Lauter FR, Russo VE, Yanofsky C (1990) Cloning, sequence, and photoregulation of al-1, a carotenoid biosynthetic gene of Neurospora crassa. Mol Cell Biol 10:5064-5070

Schmidhauser TJ, Lauter FR, Schumacher M, Zhou W, Russo VE, Yanofsky C (1994) Characterization of al-2, the phytoene synthase gene of Neurospora crassa. Cloning, sequence analysis, and photoregulation. J Biol Chem 269:12060-12066

Schmit JC, Brody S (1975) Neurospora crassa conidial germination: role of endogenous amino acid pools. J Bacteriol 124:232-242

Schmoll M, Zeilinger S, Mach RL, Kubicek CP (2004) Cloning of genes expressed early during cellulase induction in Hypocrea 
jecorina by a rapid subtraction hybridization approach. Fungal Genet Biol 41:877-887

Schmoll M, Franchi L, Kubicek CP (2005) Envoy, a PAS/LOV domain protein of Hypocrea jecorina (Anamorph Trichoderma reesei), modulates cellulase gene transcription in response to light. Eukaryot Cell 4:1998-2007

Schmoll M, Schuster A, Silva Rdo N, Kubicek CP (2009) The G-alpha protein GNA3 of Hypocrea jecorina (Anamorph Trichoderma reesei) regulates cellulase gene expression in the presence of light. Eukaryot Cell 8:410-420

Schrott EL (1980) Fluence response relationship of carotenogenesis in Neurospora crassa. Planta 150:174-179

Schuster A, Kubicek CP, Friedl MA, Druzhinina IS, Schmoll M (2007) Impact of light on Hypocrea jecorina and the multiple cellular roles of ENVOY in this process. BMC Genomics 8:449

Schwerdtfeger C, Linden H (2001) Blue light adaptation and desensitization of light signal transduction in Neurospora crassa. Mol Microbiol 39:1080-1087

Schwerdtfeger C, Linden H (2003) VIVID is a flavoprotein and serves as a fungal blue light photoreceptor for photoadaptation. EMBO J 22:4846-4855

Seibel C, Gremel G, do Nascimento Silva R, Schuster A, Kubicek CP, Schmoll M (2009) Light dependent roles of the G-alpha subunit GNA1 of Hypocrea jecorina (anamorph Trichoderma reesei). BMC Biol 7:58

Sestak S, Farkas V (1993) Metabolic regulation of endoglucanase synthesis in Trichoderma reesei: participation of cyclic AMP and glucose-6-phosphate. Can J Microbiol 39:342-347

Shaw NM, Harding RW (1987) Intracellular and extracellular cyclic nucleotides in wild-type and white collar mutant strains of Neurospora crassa: temperature dependent efflux of cyclic AMP from mycelia. Plant Physiol 83:377-383

Shinohara ML, Loros JJ, Dunlap JC (1998) Glyceraldehyde-3phosphate dehydrogenase is regulated on a daily basis by the circadian clock. J Biol Chem 273:446-452

Shrode LB, Lewis ZA, White LD, Bell-Pedersen D, Ebbole DJ (2001) $v v d$ is required for light adaptation of conidiation-specific genes of Neurospora crassa, but not circadian conidiation. Fungal Genet Biol 32:169-181

Soderhall K, Svensson E, Unestam T (1978) Light inhibits the production of alternariol and alternariol monomethyl ether in Alternaria alternata. Appl Environ Microbiol 36:655-657

Sokolovsky VY, Lauter F-R, Muller-rober B, Ricci M, Schmidhauser TJ, Russo VEA (1992) Nitrogen regulation of blue light-inducible genes in Neurospora crassa. J Gen Microbiol 138:2045-2049

Sommer T, Degli-Innocenti F, Russo VEA (1987) Role of nitrogen in the photoinduction of protoperithecia and carotenoids in Neurospora crassa. Planta 170:205-208

Sommer T, Chambers JA, Eberle J, Lauter FR, Russo VE (1989) Fast light-regulated genes of Neurospora crassa. Nucleic Acids Res 17:5713-5723

Sprote P, Brakhage AA (2007) The light-dependent regulator velvet A of Aspergillus nidulans acts as a repressor of the penicillin biosynthesis. Arch Microbiol 188:69-79
Stahl W, Sies H (2005) Bioactivity and protective effects of natural carotenoids. Biochim Biophys Acta 1740:101-107

Strigacova J, Chovanec P, Liptaj T, Hudecova D, Tursky T, Simkovic M, Varecka L (2001) Glutamate decarboxylase activity in Trichoderma viride conidia and developing mycelia. Arch Microbiol 175:32-40

Sutter RP (1970) Effect of light on beta-carotene accumulation in Blakeslea trispora. J Gen Microbiol 64:215-221

Talora C, Franchi L, Linden H, Ballario P, Macino G (1999) Role of a white collar-1-white collar-2 complex in blue-light signal transduction. EMBO J 18:4961-4968

Tamova G, Farkas V, Betina V (1995) Relationship between light intensity and the changes in the intracellular level of ATP during photoinduction in Trichoderma viride. Folia Microbiol 40 (5):516-518

Tan Y, Merrow M, Roenneberg T (2004) Photoperiodism in Neurospora crassa. J Biol Rhythms 19:135-143

Tsolakis G, Moschonas NK, Galland P, Kotzabasis K (2004) Involvement of $\mathrm{G}$ proteins in the mycelial photoresponses of Phycomyces. Photochem Photobiol 79:360-370

Tudzynski B (1999) Biosynthesis of gibberellins in Gibberella fujikuroi: biomolecular aspects. Appl Microbiol Biotechnol 52:298-310

Vargovic P, Pokorny R, Holker U, Hofer M, Varecka L (2006) Light accelerates the splicing of srh1 homologue gene transcripts in aerial mycelia of Trichoderma viride. FEMS Microbiol Lett 254:240-244

Velayos A, Blasco JL, Alvarez MI, Iturriaga EA, Eslava AP (2000a) Blue-light regulation of phytoene dehydrogenase ( $\mathrm{carB}$ ) gene expression in Mucor circinelloides. Planta 210:938-946

Velayos A, Eslava AP, Iturriaga EA (2000b) A bifunctional enzyme with lycopene cyclase and phytoene synthase activities is encoded by the carRP gene of Mucor circinelloides. Eur J Biochem 267:5509-5519

Veluchamy S, Rollins JA (2008) A CRY-DASH-type photolyase/ cryptochrome from Sclerotinia sclerotiorum mediates minor UVA-specific effects on development. Fungal Genet Biol 45:12651276

You BJ, Lee MH, Chung KR (2008) Production of cercosporin toxin by the phytopathogenic Cercospora fungi is affected by diverse environmental signals. Can J Microbiol 54:259-269

$\mathrm{Yu} \mathrm{JH}$, Keller N (2005) Regulation of secondary metabolism in filamentous fungi. Annu Rev Phytopathol 43:437-458

Yu J, Chang PK, Ehrlich KC, Cary JW, Bhatnagar D, Cleveland TE, Payne GA, Linz JE, Woloshuk CP, Bennett JW (2004) Clustered pathway genes in aflatoxin biosynthesis. Appl Environ Microbiol 70:1253-1262

Zhu JC, Wang XJ (2005) Effect of blue light on conidiation development and glucoamylase enhancement in Aspergillus niger. Wei Sheng Wu Xue Bao 45:275-278

Zurzycka A (1991) The effect of light intensity and glucose concentration on the development of Aspergillus giganteus mutant alba. Mycol Res 95:1197-1200 